\title{
Efectividad de la garantía única de cumplimiento de contratos estatales, constituida a través de póliza de seguro de cumplimiento
}

\author{
Andrés E. Ordoñez Ordoñez*
}

\section{SUMARIO}

1. Problemática general

1.1 ¿Cómo deben las entidades públicas hacer efectivos sus derechos derivados de la póliza de cumplimiento?

1.2 La vía procesal y la jurisdicción aplicable

1.3 Las defensas oponibles por parte del asegurador

2. La situación actual

3. La prescripción de la acción del asegurado contra el asegurador derivada del contrato de seguro de cumplimiento de contratos estatales

Conclusiones

Abogado de la Universidad Externado de Colombia, especialista en Derecho Privado de la misma universidad y estudios en Derecho y Economía Bancarios de la Universidad de París. Docente de Derecho Civil y de la Maestría en Derecho de Seguros de la Pontificia Universidad Javeriana en el seminario de jurisprudencia y doctrina. Coordinador de la Sección Jurisprudencial de nuestra revista.

Correo electrónico: aeooa@colomsat.net.co 


\section{RESUMEN}

El presente artículo examina las características y problemáticas de la póliza de seguro de cumplimiento que se presentan específicamente en el ámbito de cumplimiento de contratos estatales. El autor investiga la efectividad de la misma en el contexto colombiano, desde sus primeros rastros hasta la situación de regulación actual, sus deficiencias, su jurisdicción aplicable, y por supuesto las facultades de las entidades estatales en el tema. En seguida el autor explora las soluciones a la problemática.

Palabras Clave: Cumplimiento, Garantía, Seguro, efectividad, problemática, deficiencias, estatal, contratos.

Palabras clave descriptor: Póliza de cumplimiento, garantía única, entidades públicas, defensas oponible, jurisdicción aplicable

\section{AbStract}

This manuscript reviews the features and problems of a performance insurance policy (performance bond) in the context of public contracts. The author conducts some research about the effectiveness of such insurance policy in the Colombian context, from its origins through the present days of regulations, and also about its deficiencies, its applicable jurisdiction, opposable defenses and of course, the faculties of the governmental entities to that respect. Afterwards, the manuscript explores some solutions to the problems posed by that insurance policy (performance bond).

Word keys: Performance, guarantee, insurance, effectiveness, problematic, deficiencies, State, contracts.

Word keys plus: performance insurance policy (performance bond), sole guarantee, public entities, opposable defenses, applicable jurisdiction, performance insurance policies statute of limitations, public contracts 


\section{PROBLEMÁTICA GENERAL}

Las dificultades tradicionales que presenta la efectividad de las garantías únicas de cumplimiento de contratos estatales, vertidas bajo la forma de seguros de cumplimiento:

Es bien sabido que antes de la vigencia del Código de Comercio, esto es, antes de 1971, fue necesario, ante el limitado alcance del concepto de "riesgo asegurable" que consagraba el Código de Comercio entonces vigente, expedir una ley especial, la Ley 225 de 1938, para darle marco legal y consecuencial viabilidad a lo que se llamó el seguro de manejo y cumplimiento. De la simple lectura de esa ley, de muy escasa extensión se deduce claramente que uno de sus objetivos fundamentales fue permitir la implementación, al lado del seguro de manejo para los empleados públicos de confianza y manejo, de un sistema de garantía de cumplimiento de los contratos celebrados por entidades públicas, de tal manera que fuera posible que compañías aseguradoras, tradicionalmente dotadas de sólida solvencia, asumieran el pago de los perjuicios que eventualmente pudiera sufrir el Estado con motivo del incumplimiento de dichos contratos.

La intención claramente era la de que las aseguradoras en desarrollo de su objeto social característico, expidieran contratos de seguro en esa modalidad creada legalmente en forma expresa, sin que se consagrara, desde entonces, respecto de los mismos, excepción alguna al régimen jurídico propio de los contratos de seguro en general.

Ahora bien, dentro de este contexto, como era de esperarse, no se previeron los problemas que podrían surgir al convertirse el seguro de cumplimiento en la modalidad de garantía más utilizada desde entonces dentro del ámbito de la contratación pública, dada la necesidad de que esa garantía fuera suficientemente eficaz para proteger el patrimonio estatal, ante las características especiales del contrato de seguro 
y la manera propia de actuar, en la teoría y en la práctica, de las entidades públicas aseguradas. Cómo debían ellas ejercer sus derechos derivados del contrato de seguro de cumplimiento (cómo podían hacer efectivas las garantías), qué vía procesal debía utilizarse para el efecto, asunto que incluía la determinación de la jurisdicción aplicable en caso de conflicto y, sobre todo, qué defensas podría eventualmente esgrimir el asegurador contra la asegurada dada la disciplina propia del contrato de seguro.

Es muy difícil seguir el rastro histórico de la evolución que el tratamiento de estos problema experimentó desde el momento en que se expidió la ley del año 38, pero el hilo de esa evolución se hace más identificable a partir de la expedición del Estatuto de Contratación Administrativa consagrado mediante el decreto 150 de 1976 y del largo proceso de debates constitucionales que precedieron a la adopción definitiva del hoy artículo 68 del Código Contencioso Administrativo. Vale la pena mencionar que el decreto 150 en su artículo 58 dispuso luego de hablar en normas anteriores sobre las garantías en general, que ellas podrían consistir en "fianzas" de compañías de seguro o de bancos, y no utilizó la expresión "seguro de cumplimiento" y que en similar sentido se pronunció el artículo 70 del decreto 222 de 1983; el numeral 19 del artículo 25 de la Ley 80 de 1993, en cambio, estableció: "Las garantías podrán consistir en pólizas expedidas por Compañías de Seguro...." expresión que conserva la Ley 1150 en su artículo 7으, y que concreta finalmente el decreto 4828 al señalar en su artículo 15 al decir: "De conformidad con lo previsto en el inciso 2 o del art. 7o de la Ley 1150 de 2007, la póliza única de cumplimiento...".

\section{1 ¿Cómo deben las entidades públicas hacer efectivos sus derechos derivados de la póliza de cumplimiento?}

En cuanto a este primer punto, sobre cómo debían las entidades públicas hacer efectivos sus derechos derivados de la póliza de seguro, era fundamental en primer lugar establecer en qué consiste el siniestro en este tipo de pólizas y cuándo debe entenderse ocurrido. Es claro, en primer lugar que el siniestro, si se trata de un seguro de cumplimiento, está constituido por el incumplimiento, pero en este caso, por la ya mencionada particular manera de actuación de las entidades públicas, se consideró necesario establecer cuándo debe entenderse ocurrido, no el incumplimiento, sino el siniestro para los efectos de la póliza, sobre todo desde el momento en que se tenía ya bien decidido que esa póliza debería poder prestar mérito ejecutivo y que las entidades públicas deberían gozar de ciertas prerrogativas en ese sentido, tales como el de poder utilizar para ello a la jurisdicción coactiva y el de no depender de la no objeción de la Compañía de Seguros para que la póliza pudiera prestar mérito ejecutivo en su favor, como ocurría en todos los demás ramos del seguro. No se olvide que el esquema normal del mérito ejecutivo de la póliza en general se trazó en Colombia desde la expedición de la Ley 105 de 1927.

El siniestro en la garantía única de cumplimiento no estaba y nunca estuvo definido legalmente durante muchos años. Se definió tradicionalmente por cláusula contractual en el texto de las pólizas entonces llamadas de cumplimiento de contratos adminis- 
trativos redactadas con base en el modelo que, según todos recordamos, fue objeto de aprobación a través de los años por resoluciones de la Contraloría General de la República por disposición originalmente de la ya mencionada Ley 225 de 1938 y de su decreto reglamentario 1348 de 1939 y posteriormente de los estatutos de contratación administrativa. Es difícil seguir el rastro completo de los actos de la Contraloría a través de los cuales se cumplió ese propósito, pero podría mencionarse inicialmente la Resolución 1810 de 1957 complementada luego por las Resoluciones 2075, 2086 y 2092 de 1960, pasando por la Resolución 8428 de 1980 que fue rápidamente sustituida por la 8660 de 1981 y luego por la número 10050 de 1984, de validez discutible por cuanto fue expedida cuando ya estaba vigente la Ley 222 de 1983. El artículo 70 del decreto ley 222 de 1983 traspasó la facultad de aprobación de los textos de las pólizas correspondientes a la Superintendencia Bancaria. La entidad a través del oficio DS y C 2043 de 23 de abril de 1985, aprobó a todas las compañías afiliadas a Fasecolda, la póliza matriz de Seguro de Cumplimiento para entidades oficiales que comenzaría a regir a partir del mes de agosto de 1985.

Actualmente, como ya se vio, cuando esa aprobación ya no es necesaria conforme a la ley, la definición del siniestro queda concretada exclusivamente al texto de las cláusulas contractuales, las cuales en general han conservado a este respecto la misma redacción de las pólizas anteriores.

Pero a este respecto debe hacerse una claridad ineludible: el análisis de la evolución de los textos de las pólizas matrices aprobadas por la Contraloría General de la República que pasaron a los textos de las pólizas expedidos por las compañías de seguro, demuestran que nunca se pretendió en la definición básica del siniestro, alterar el alcance las facultades de expedición de actos unilaterales que las entidades públicas tienen conforme a la ley dentro de su actividad contractual. Ello sería completamente ilógico puesto que significaría auspiciar un tratamiento diferencial, desde el punto de la entidad pública, para el contratista y para el asegurador del contratista, hasta el punto de anularse cualquier limitación del poder de la entidad pública como contratante dentro del contrato estatal, pudiendo desentenderse completamente de esas limitaciones para perseguir sin ningún obstáculo y dentro de una arbitrariedad casi absoluta a su asegurador, independientemente de la realidad existente en su relación con el contratista.

Una de las primeras las resoluciones de la Contraloría General de la República que reguló este tema, dentro de la evolución indicada anteriormente, la distinguida con el número 1810 de 1957, establecía que debía entenderse causado el siniestro "Tan pronto como la aseguradora sea notificada de las resoluciones administrativas que declaren el incumplimiento del contrato o de alguna de sus estipulaciones, o de imposición de multas o sanciones previstas en el mismo". Como se puede observar claramente, en su origen, se hacía mención a un acto administrativo muy característico, el que declara el incumplimiento del contrato o el que impone multas o sanciones. Es completamente obvio a nuestra manera de ver, que la definición del momento en que se entiende causado el siniestro, dentro de este contexto, depende de la manera 
como es entendida la facultad de las entidades públicas de declarar la caducidad o el incumplimiento del contrato. Solo posteriormente, en la Resolución 08660 de 1981, la enumeración de los eventos en los que debe entenderse causado el siniestro, todos ellos referidos a la notificación al asegurador de actos administrativos de diferente naturaleza, al lado de la mención en el numeral 10 de las resoluciones de caducidad o incumplimiento del contrato, aparece en el numeral $2^{\circ}$ una referencia a la resolución administrativa que "...declare la ocurrencia del riesgo que ampara el seguro". Este esquema pasó directamente al texto aprobado por la Superintendencia Bancaria en 1985.

Dentro de ese marco es que se ha venido entendiendo siempre que el siniestro en las pólizas de cumplimiento de contratos estatales y hoy en las garantías únicas de cumplimiento de contratos estatales, está constituido por el acto administrativo que declara la caducidad o impone la obligación de pagar la cláusula penal o las multas en caso de incumplimiento, o por el acto administrativo que declare la realización de los demás riesgos amparados.

Como se verá más adelante, este diseño que resulta necesariamente un tanto artificial, en lo que se refiere a la determinación del momento en que ocurre el siniestro, es lo que ha hecho adicionalmente complejo el tema relativo a la prescripción de las acciones de las que disponen las entidades públicas para el cobro de las indemnizaciones frente a las compañías de seguro.

Se advierte de inmediato la desarmonía de esas estipulaciones contractuales, con la realidad de la evolución que venía teniendo, en la ley y en la jurisprudencia, la concepción acerca del alcance de las facultades que la administración tiene para llevar a cabo actos administrativos unilaterales de naturaleza contractual, en los que se asuma una condición de preeminencia frente al particular y se hagan declaraciones atinentes al incumplimiento del mismo, se le impongan sanciones o de cualquier otra manera se hagan declaraciones que en un contrato entre particulares serían de privativa competencia de la autoridad jurisdiccional.

Prueba de que existe una clara conciencia de ello en el Consejo de Estado es que solo excepcionalmente y de manera muy marginal, la jurisprudencia que se ha generado sobre la materia, reconoce que la facultad de las entidades estatales para producir el acto administrativo mediante el cual se declara la ocurrencia del riesgo, deriva del texto de las pólizas de seguro. Siempre ha acudido, como se verá, sea al artículo 68 del C.C.A., o a la ya abandonada idea de la "fuerza ejecutoria" o "privilegio de la decisión previa" de la cual disfrutan los actos administrativos.

\section{En efecto:}

No debe olvidarse, que desde hace muchos años en Colombia, la norma básica que regula la efectividad de las pólizas de seguro de cumplimiento expedidas a favor de entidades públicas, está consagrada en el Código Contencioso Administrativo y es el artículo 68 de ese estatuto en sus numerales $4 \underline{0}$ y $5^{\mathfrak{0}}$. 
Esta disposición fue el producto de controversias muy extensas que son recordadas todavía, relativas a la legalidad de disposiciones que se tomaron en el mismo sentido en los estatutos de contratación administrativa que rigieron con anterioridad, en los cuales se insistió por gobiernos sucesivos, a través de decretos, en proveer de fuerza ejecutiva por jurisdicción coactiva a estas pólizas, estando en duda sus facultades para legislar a este respecto, y se incurrió en imprecisiones y errores en cuanto a la manera de integrar los títulos ejecutivos correspondientes en estos casos.

Como no es necesario reproducir esos debates, basta decir simplemente que los mismos culminaron con la expedición del decreto con fuerza de Ley 01 de 1984, actual Código Contencioso Administrativo, el cual, ya sin que existieran dudas en torno a las facultades del Ejecutivo para el efecto, establecieron en los ya mencionados numerales $4^{\circ}$ y $5^{\circ}$ del artículo 68 dos disposiciones regulatorias del tema de las garantías y concretamente de los seguros de cumplimiento expedidos a favor de entidades públicas, para establecer que ciertamente esas pólizas prestarían mérito ejecutivo por jurisdicción coactiva dentro de ciertas circunstancias.

Ahora bien, debe observarse que estos numerales del artículo 68 están precedidos de un encabezamiento dirigido inequívocamente a señalar que la finalidad de la norma es definir documentos que prestan mérito ejecutivo por jurisdicción coactiva "... siempre que en ellos conste una obligación clara, expresa y actualmente exigible...". La jurisdicción coactiva se define como "una función jurisdiccional asignada a un organismo o a un funcionario administrativo determinado para que, sin recurrir a la autoridad judicial, haga efectivas, por la vía ejecutiva, las deudas fiscales expresas, claras y exigibles a favor de la entidad pública que ejerce dicha jurisdicción"11.

De tal manera que la intención del Código Contencioso en la norma que se comenta, es no solo darle mérito ejecutivo a determinados documentos que incorporan obligaciones a favor de las entidades públicas, sino establecer para el cobro ejecutivo de los mismos un procedimiento especial ante autoridades administrativas.

La siguiente observación que es fundamental y que notoriamente fue desestimada particularmente por la jurisprudencia administrativa en Colombia durante mucho tiempo, al mezclarlos indiscriminadamente, es que los dos numerales están dirigidos a pólizas de seguro de cumplimiento a favor de entidades públicas diferentes. Así, el numeral $4^{\mathrm{O}}$ se refiere inequívocamente a seguros de cumplimiento de contratos estatales, al referirse a "Los contratos, las pólizas de seguro y las demás garantías que otorguen los contratistas a favor de entidades públicas...." (El subrayado no es del texto), mientras que el numeral 5o se refiere a "Las demás garantías que a favor de las entidades públicas se presten por cualquier concepto...". En el primer caso la ley hace referencia clara a los seguros de cumplimiento de contratos, esto es a los seguros de cumplimiento de obligaciones de origen contractual, nacidas de contratos, en

1 Escobar Vélez, Edgar Guillermo: El proceso de jurisdicción coactiva. Señal Editora. Segunda edición Medellín, 1999, pág. 19. 
el segundo, por exclusión, en lo que se refiere a pólizas de seguro de cumplimento, alude a los de cumplimiento de obligaciones de origen diferente, las que derivan de la ley directamente, que constituyen el otro único tipo de obligaciones que son susceptibles de aseguramiento mediante pólizas de seguro, obligaciones generalmente de naturaleza tributaria o aduanera.

Un ejemplo, entre innumerables, de la confusión en la que al respecto incurrió con frecuencia el Consejo de Estado, al tratar indistintamente los supuestos de hecho de los numerales 4 y y 50 del artículo 68 del C.C.A, es la sentencia de julio 10 de 1997, proferida dentro del expediente 9286 con ponencia del Doctor CARLOS BetanCUR Jaramillo. En esta sentencia, se admite ampliamente la posibilidad de que las entidades públicas procedan a declarar el siniestro de estabilidad de obra, aún con mucha posterioridad al vencimiento del término contractual y al de su liquidación, apelando al numeral 5o del artículo 68 del C.C.A., lo cual no solo va en contra de la clara intención de la ley sino de todas las tendencias jurisprudenciales que están dirigidas a limitar en términos razonables el poder de las entidades administrativas para proferir actos administrativos de naturaleza unilateral.

Esto indica que la definición legal sobre conformación de títulos ejecutivos con pólizas de seguro debe leerse con atención a esta clara diferenciación que establecen los dos numerales comentados. Solamente en muy recientes decisiones la Sección III del Consejo de Estado accedió finalmente a reconocer esta diferencia, pero dedujo de ella consecuencias que son claramente erradas. Ello ocurrió por primera vez en sentencia de 14 de abril de 2005 con ponencia del Dr. Alier EduARDo HeRNÁNDEZ, dentro del expediente 13599. Allí, descartando la tesis anterior, y, repito, no obstante reconocer la diferencia entre los numerales 40 y $5^{\circ}$ del artículo 68 del C.C.A., el Consejo consideró, contra toda evidencia, que no obstante esa diferencia, no podía discutirse la facultad de las entidades públicas para declarar la ocurrencia de los siniestros respecto de las pólizas de seguro de cumplimiento. A esta sentencia corresponden los siguientes apartes:

"En segundo lugar, y partiendo de la vigencia del numeral 4 citado, éste regula y se refiere expresamente a las relaciones de naturaleza contractual, cuando los contratistas constituyen pólizas a favor del Estado, las cuales, junto con el acto administrativo de liquidación, la declaratoria de caducidad o la terminación, prestan mérito ejecutivo. Ahora bien, el numeral 5 establece que cualquier otra garantía presta mérito ejecutivo a favor del Estado, junto con el acto administrativo que declara la correspondiente obligación.

Para la Sala estas dos normas se deben integrar, para comprender su alcance y significado plenos, integración de la cual resulta que cualquier póliza contractual, constituida a favor del Estado, presta mérito ejecutivo -aunque no por jurisdicción coactiva-, pues no es lógico -ni es el sentido de la normafraccionar el mérito ejecutivo de las garantías contractuales a favor del Estado, cuando es claro que el numeral 4 citado incluye todos los amparos que puede 
contener una póliza; y el numeral 5 incluye cualquier otro tipo de garantía a favor del Estado, de donde se deduce que el propósito mismo de la norma es el de otorgar una prerrogativa a las entidades estatales para que puedan declarar ellas mismas el siniestro, y hacerlo exigible en forma efectiva.

Incluso una interpretación exegética de las normas citadas permite llegar a esta conclusión, pues bien dice el numeral 5 que todas las garantías constituidas a favor del Estado -sin exclusión- prestan mérito ejecutivo; y el numeral 4 se refiere específicamente -a las contractuales-, normas estas que no se excluyen entre sí, sino que se complementan en su interpretación".

En buena hora el Consejo de Estado, en esta misma sentencia, volvió sobre la doctrina muy discutible que había sostenido en sentencia de 24 de mayo de 2001 (Rad. 0296. Número interno 13598) como último y desesperado recurso para sostener la existencia de la facultad de las entidades estatales para declarar en cualquier tiempo la realización del siniestro cubierto por la póliza de cumplimiento, en el sentido de que esa facultad derivaba del llamado "privilegio de la decisión previa". En efecto: en la sentencia mencionada de 14 de abril de 2005, reiterada recientemente en providencia del nueve (9) de agosto del año pasado, con ponencia del Doctor MAURICIO FAJARDO dentro del expediente 21432, que será citada repetidamente más adelante, dijo el Consejo de Estado:

“(...) considera esta Sala imperioso precisar ahora que la ilegalidad, por falta de competencia, para proferir un determinado acto administrativo no se puede purgar a través del "privilegio de decisión previa" porque si bien éste supone la toma de decisiones por parte del Estado sin necesidad de contar con el consentimiento de los afectados o con la anuencia previa del juez, éstas sólo pueden ser adoptadas en ejercicio de una competencia establecida en la ley. Así, el privilegio de lo previo no constituye el fundamento de la competencia; por el contrario ésta es un presupuesto necesario de aquél. De otra manera, se desconocerían los artículos 122 de la Constitución Política -según el cual no habrá empleo público que no tenga funciones detalladas en ley o reglamentoy 84 del C.C.A., en cuanto dispone que la acción de nulidad contra los actos administrativos puede fundarse en el hecho de que los mismos hayan sido expedidos por funcionarios $u$ organismos incompetentes.

"Lo anterior, sin embargo, no obsta para considerar, como lo hizo la Sala en la sentencia del 24 de mayo de 2001, que son válidos los actos administrativos por los cuales la entidad contratante decidió hacer efectiva la póliza que garantiza la estabilidad de la obra contratada, al declarar la ocurrencia del riesgo amparado. En efecto, no cabe duda de que aquélla contaba, para hacerlo, con una facultad legal expresa, prevista en los numerales $4^{\circ}$ y $5^{\circ}$ del art. 68 del C.C.A., en los cuales se relacionan los actos que prestan mérito ejecutivo". 
A nuestra manera de ver esa asimilación de los dos numerales del artículo 68 del C.C.A. por parte del Consejo de Estado es inaceptable. En el primer caso, el del numeral 4 o, la póliza de seguro se integrará, con el acto administrativo de liquidación final del contrato, o con la resolución ejecutoriada que decrete la caducidad, o la terminación en su caso; en el segundo caso con el acto administrativo ejecutoriado que declare la obligación. Y no pueden confundirse la dos clases de pólizas, porque, repito el texto legal es suficientemente claro en este punto.

Al producirse la expedición de la Ley 80 de 1993, el Consejo de Estado, tomando partido respecto de la interpretación que debe darse al artículo 75 de la ley que otorga a la jurisdicción Contencioso Administrativa la competencia para conocer "... de las controversias derivadas de los contratos estatales y de los procesos de ejecución o cumplimiento..." sostuvo en una de sus providencias la derogatoria del numeral 4 o del artículo 68 del Código Contencioso Administrativo, en el sentido de que los procesos ejecutivos que se adelantan con base en pólizas de cumplimiento de contratos estatales contra las aseguradoras, no pueden llevarse a cabo por la jurisdicción coactiva sino ante el juez contencioso administrativo. No obstante que las decisiones a este respecto no fueron inicialmente claras, lo cierto es que debía entenderse que la derogatoria tal como fue entendida, por el Consejo de Estado, existió en lo que se refiere a la competencia para conocer de los procesos ejecutivos y no en cuanto a la naturaleza y manera de integrar el título ejecutivo, pues a este respecto el artículo 68 del Código Contencioso Administrativo sigue siendo la norma existente que regula la materia ${ }^{2}$. Prueba de ello, es que el Consejo de Estado siguió invocando esta norma para derivar de ella la potestad que a su juicio tienen las entidades estatales para expedir actos administrativos unilaterales que declaren la ocurrencia de los siniestros cubiertos por las pólizas de cumplimiento.

Esta conclusión quedó ampliamente confirmada al suspenderse provisionalmente artículo 19 del decreto 679 de 1994, por ser considerado contrario precisamente a lo dispuesto por el artículo 75 de la Ley 80, mediante auto de la Sección del Consejo de Estado, dictado el 27 de febrero de 1997 dentro del expediente 11318 con ponencia del Doctor Jesús María CarRILLo.

En cuanto a la mencionada derogatoria del artículo 68 del C.C.A., la sentencia de nueve (9) de agosto del año pasado, con ponencia del Doctor MAURICIO FAJARDO dentro del expediente 21432, reproduciendo el fallo de 14 de abril de 2005 (Ex 1359) ya citado, señala claramente lo que se había anunciado, esto es, que no existe tal derogatoria sino en lo que se refiere a la jurisdicción aplicable a esta clase de títulos ejecutivos.

2 Sección V del Consejo de Estado. Sentencia de 26 de enero de 1996, Expediente 0585. Actor: Juzgado Único de Ejecuciones Fiscales. Reitera doctrina acogida por la misma sección en expedientes números 0528, 0537 y 0539 . Reiterada en sentencias de la misma sección: 19 de febrero de 1996, expediente 0597, 19 de febrero de 1996, expediente 0599, 26 de febrero de 1996, expediente 0575, 22 de julio de 1996 expediente 0678, 4 de junio de 1998 expediente 1032 y 16 de diciembre de 1999 expediente 1202. 
"La sentencia en cita se pronunció en los siguientes términos respecto de esta facultad, con ocasión de la expedición del artículo 75 de la Ley 80 de 1993, a través del cual el legislador atribuyó al juez de lo Contencioso Administrativo la competencia para conocer de los procesos de ejecución derivados de los contratos estatales:

“De modo que la derogatoria ocurrida, según lo entendió entonces la Sala, se circunscribe a la atribución de competencias, para los procesos ejecutivos, a la jurisdicción Contencioso Administrativa, despojando de la misma a la jurisdicción coactiva, pero no se extiende a la posibilidad de dictar los actos administrativos a que dicha norma se refiere, ni a la conformación del título ejecutivo; luego el numeral 4 del artículo 68 sigue vigente, en cuanto al hecho de que indiscutiblemente los actos allí relacionados prestan mérito ejecutivo, pues esto no contraviene la Ley 80 de 1993, luego no se ha operado una derogación tácita en este sentido; lo que sí quedó derogado fue el hecho de que dichos actos presten mérito ejecutivo por jurisdicción coactiva, pues el artículo 75 de la Ley 80 ha dispuesto que los procesos de ejecución, derivados de los contratos estatales, sean de conocimiento de la Jurisdicción Contencioso Administrativa. $* * *$

'Lo anterior permite deducir que, una vez declarado el incumplimiento de las obligaciones del contratista y configurado el siniestro, se ordenará hacer efectiva la garantía otorgada, mediante acto administrativo, el cual podrá ser objeto de recursos en la vía gubernativa, pero la ejecución no podrá tramitarse mediante el procedimiento de la jurisdicción coactiva, sino mediante el proceso ejecutivo ante esta jurisdicción (...)'. (Subrayas fuera de texto). Sentencia de 24 de agosto de 2000, exp. 11318, C.P. Jesús María Carrillo".

Este primer aparte, nos permite concluir, en primer lugar, que el punto de las facultades con las que cuentan las entidades estatales para expedir actos unilateral mediante los cuales declaren la ocurrencia de los siniestros que afecta las garantías vertidas bajo la forma de pólizas de cumplimiento, siempre ha estado en entredicho, por decir lo menos, contradice ciertamente la filosofía que inspira el estatuto de contratación estatal en lo que se refiere a la posición de esas entidades frente a sus propios contratistas y es inconveniente como se verá más a espacio en lo que sigue, así como se analizará hasta qué punto la nueva legislación (ley 1150 de 2007 y decreto 4828 de 2008) soluciona o no, este problema; en segundo lugar, que radicar el hecho del siniestro no en el incumplimiento físico del contratista, sino en la expedición de un acto administrativo, anticipa dos problemas que no tienen una adecuada solución hasta hoy, a saber: que si ello es así, resulta obvio que el acto administrativo debe ser expedido dentro de la vigencia de la póliza, algo que las entidades estatales han demostrado estar generalmente en incapacidad de lograr, puesto que es claro que un siniestro ocurrido por fuera de la vigencia de la póliza no puede estar cubierto, y, además, que el término de prescripción o caducidad de cualquier acción que puedan tener las entidades estatales para cobrar el seguro, no puede comenzar a correr antes de la expedición de ese acto, puesto que no puede entenderse que exista esa acción 
sin que haya ocurrido el siniestro. Estos dos hechos que son ineludibles han obligado, como se verá más adelante a que el Consejo de Estado concrete unas doctrinas sobre el particular que resultan particularmente discutibles por ser incoherentes.

\subsection{La vía procesal y la jurisdicción aplicable}

El tema de la vía procesal y de la jurisdicción aplicable se orientó con base en los esfuerzos de los sucesivos gobiernos de hacer lo más expedita posible la discusión procesal en torno a la eficacia de las pólizas, lo que llevó a la persistente insistencia no siempre desarrollada por cauces constitucionales, ya mencionada, por habilitar para estos efectos tanto el proceso ejecutivo como la jurisdicción coactiva. Por lo mismo, la culminación de estos esfuerzos se produjo según lo visto con la consagración del artículo 68 del C.C.A., que estableció de una vez por todas que las pólizas de cumplimiento a favor de entidades estatales, sin distinción dentro de las muchas clases que de ellas existen, prestan mérito ejecutivo o están en capacidad de integrar un título que preste mérito ejecutivo, siempre que de ellas se pueda deducir una obligación expresa, clara y actualmente exigible a cargo del deudor.

No obstante, tampoco se ha advertido el hecho de que no es el proceso ejecutivo la única vía procesal de la que disponen las entidades públicas para hacer efectivos sus derechos derivados de las pólizas de cumplimiento, ya que como ocurre con cualquier tipo de obligaciones independientemente de la clase de documentos en los que conste, el acreedor es libre de utilizar la vía ordinaria siempre que por cualquier circunstancia prefiera esa vía, antes que someterse a un debate previo sobre la formalidad del título que usualmente es el primer escenario de conflicto en un proceso ejecutivo. Es por eso que resulta completamente viable que la entidad pública decline integrar un título ejecutivo con su póliza de seguro de cumplimiento y acuda al juez del contrato para obtener del mismo, en juicio contractual ordinario, la declaratoria de incumplimiento y la condena al asegurador, con lo cual descarta además cualquier ulterior discusión sobre la legalidad de su propio acto administrativo que, como bien se sabe, es una discusión que puede paralizar casi indefinidamente, por prejudicialidad, cualquier proceso ejecutivo iniciado con anterioridad. También el proceso ordinario puede tener la ventaja de obtener directamente del juez la liquidación del contrato que, de tener que ser llevada a cabo directamente por la entidad pública, no solamente puede faltar por no haberse procedido a realizarla oportunamente, sino que está más que ningún otro acto administrativo sujeto a controversias de la más diversa índole; todo ello dentro del contexto olvidado repetidamente por las entidades públicas, de que ese acto es un requisito indispensable en la mayoría de los casos cuando quiere disponerse de un título ejecutivo contra el asegurador, porque es el único que puede hacer en la mayoría de los casos, de la obligación, una obligación expresa, clara y actualmente exigible.

El Consejo de Estado ya ha reconocido la posibilidad de este tipo de acciones ordinarias, frente a situaciones en las que la entidad estatal ha expedido un acto administrativo de terminación unilateral del contrato por existir a su juicio una causal de 
nulidad del mismo; aquí la entidad estatal antes que acudir a una acción ejecutiva, prefirió acudir al juez (la Jurisdicción Contencioso Administrativa) a fin de que declarara la ocurrencia del siniestro de apropiación indebida del anticipo e incumplimiento por parte del contratista, y consecuencialmente condenar al asegurador a pagar las indemnizaciones correspondientes con base en las coberturas de la póliza que garantizaba el contrato; pero asimismo, no existen razones para que ello no ocurra de la misma manera sin que exista siquiera acto administrativo alguno. Nuevamente, en este caso lo único que se opone teóricamente a esta alternativa, es una pura cuestión de forma y es que alguien podría afirmar que puesto que el siniestro es el acto administrativo que lo declara, mientras no exista ese acto administrativo no se podría adelantar la acción. Una cuestión relativa a una mala comprensión del riego cubierto por la póliza.

En cuanto a la jurisdicción ante la cual debería adelantarse el proceso ejecutivo, ya se sabe que la solución legal no ha llegado de manera definitiva y que seguimos debatiendo si debe ser la jurisdicción ordinaria, o la Contencioso Administrativa o la jurisdicción coactiva la que se ocupe de estos temas. Al interior de la sección III del Consejo de Estado sigue existiendo un debate al respecto, aunque la tesis mayoritaria parece ser desde hace algún tiempo y en la actualidad, que es a la Jurisdicción Contencioso Administrativa a la que corresponde el conocimiento de los procesos ejecutivos que se adelantan por parte de las entidades estatales contra la aseguradora con base en las pólizas de cumplimiento de contratos estatales. Para adoptar esta tesis, se ha acudido a razonamientos del más diverso tipo; los más sobresalientes son los siguientes:

a) El contrato de seguro de cumplimiento de contratos estatales es un contrato estatal; argumento que era hace algún tiempo el menos aceptado por cuanto también mayoritariamente el Consejo de Estado ha sostenido que generalmente este es un contrato de naturaleza privada que se celebra entre particulares (el contratista y el asegurador), pero tesis que ha sido reiterada recientemente, como puede verse en la sentencia del pasado agosto seis (06) de dos mil nueve (2009), de la Sección III, con ponencia del Dr. MAURICIO FAJARDO, radicación 250002326000199704694-01 (22.339), la cual reitera lo dicho en dos providencias anteriores, donde se expresó en forma contundente:

"Se confirmará la decisión impugnada, toda vez que esta Sección del Consejo de Estado reafirmó la tesis jurisprudencial según la cual la Jurisdicción Contencioso Administrativa es competente para conocer de los procesos ejecutivos, cuya fuente radica en los contratos de seguro celebrados por el contratista y la compañía aseguradora, para garantizar el contrato estatal; es así como en auto de 30 de enero de 2008, reiterado en providencia calendada en abril 9 del mismo año, -a manera de síntesis- se concluyó que:

"...(...)...

2.4. Competencia de la Jurisdicción de lo Contencioso Administrativo para conocer de procesos ejecutivos derivados de los contratos de seguro de cumplimiento de contratos estatales.

RIS, Bogotá (Colombia), 37(21): 149-190, julio-diciembre de 2012 
En cuanto ha quedado establecido que los contratos de seguro que se celebren para garantizar el cumplimiento de los contratos de las entidades estatales también pertenecen a la misma categoría de los contratos estatales, se impone concluir entonces que la competencia para conocer tanto de las controversias que se deriven de los mismos como de los procesos de ejecución que en ellos se originen, se encuentra legalmente asignada a la Jurisdicción Contenciosa Administrativa (...)". (Subrayas fuera de texto).

Esta tesis ha venido a ser, apoyada con dos argumentos adicionales sobre los cuales debo llamar la atención, toda vez que uno de ellos se refiere a un punto que juzgo particularmente importante. En efecto, con base en lo que dispone el artículo 1.047 del Código de Comercio, en el sentido de que las partes que intervienen en el contrato de seguro son el tomador y el asegurador, se consideraba tradicionalmente que, como por una vieja costumbre nacionalmente difundida, se hace figurar como tomador del seguro de cumplimiento de contratos estatales al contratista que es a la vez afianzado, el seguro no era un contrato celebrado por la entidad estatal sino por particulares y en consecuencia no podía ser considerado estatal. La nueva observación del Consejo de Estado, se orienta a señalar cómo la entidad pública sí debe considerarse parte en la medida en que es indudable que su interés está de por medio en el contrato y a ella competen muchas de las obligaciones propias del tomador del seguro y que, por ello, no obstante no aparecer literalmente como tomador en la póliza, no debe desconocerse su posición de tal. Esta posición ha sido expuesta in extenso en el auto de 30 de enero de 2008 con ponencia del Dr. Mauricio Fajardo Gómez, cuya radicación es: 52001-23-31-000-2005-00512-01(32867).

A esta sentencia corresponden los siguientes apartes que vale la pena transcribir:

"Para la Sala resulta válido sostener que en los contratos de seguros que se celebran con el fin de garantizar el cumplimiento de contratos estatales, las entidades contratantes sí toman parte.

El anterior aserto se explica con toda naturalidad en cuanto la relación contractual en estudio se examine a la luz de la institución de la estipulación a favor de otro, en virtud de la cual la ley autoriza a cualquier persona para que convenga a favor de un tercero, sin contar con derecho alguno para representarlo, en el entendido de que sólo ese tercero podrá exigir lo estipulado una vez acepte, de manera expresa o tácita, la respectiva convención.

Después de examinar el alcance de la norma legal que en el derecho común regula, de manera general, la institución de la estipulación a favor de un tercero, contenida en el artículo 1506 del Código Civil, se evidencia que la aceptación que el tercero manifiesta respecto de la estipulación que se ha efectuado a su favor genera efectos retroactivos al momento de la celebración de la convención entre estipulante y prometiente, al tiempo que determina el surgimiento de una relación contractual entre el beneficiario y el prometiente, en virtud de la cual, 
precisamente, aquél en condición de acreedor podrá exigirle al prometiente el cumplimiento de su obligación.

Y se entiende con facilidad que la obligación que el prometiente asume para con el beneficiario y que sólo éste puede exigirle, también encuentra sustrato en la relación contractual que se concluye entre dichos prometiente y beneficiario, como quiera que la manifestación de voluntad que realiza tal prometiente en acuerdo con el estipulante, en el sentido de obligarse a favor del beneficiario, encuentra como respuesta la aceptación incondicional de éste; ¿Y qué tipo de relación jurídica existe acaso entre dos partes, cuando las mismas concluyen un acuerdo de voluntades que genera obligaciones, si no es una relación de índole contractual?

$* * *$

"Si bien resulta cierto que la figura de la estipulación a favor de un tercero, a partir de su regulación general, aporta elementos trascendentes para dilucidar la problemática relacionada con la naturaleza jurídica de los contratos de seguro de cumplimiento de contratos estatales, no es menos cierto que ante la existencia de una norma legal especial que consagra y disciplina esa misma institución para el caso del contrato de seguro, se impone la aplicación preferente de dicha disposición especial a cuyo amparo deberá adelantarse el estudio de la materia en cuestión.

Esa regla especial, para los contratos de seguros, se encuentra contenida en el artículo 1038 del Código de Comercio, a cuyo tenor:

"Artículo 1038.- Si el tomador estipula el seguro en nombre de un tercero sin poder para representarlo, el asegurado puede ratificar el contrato aún después de ocurrido el siniestro. El tomador está obligado personalmente a cumplir las obligaciones derivadas del contrato, hasta el momento en que el asegurador haya tenido la noticia de la ratificación o del rechazo de dicho contrato por el asegurado.

Desde el momento en que el asegurador haya recibido la noticia de rechazo, cesarán los riesgos a su cargo y el tomador quedará liberado de sus obligaciones, sin perjuicio de lo dispuesto en el artículo 1119."

Para la Sala, la hipótesis fáctica prevista en la norma legal que acaba de transcribirse es, precisamente, la que se configura en el caso de los contratos de seguro que se vienen mencionando, como quiera que el contratista particular, sin contar con poder alguno o con facultad para representar y menos para vincular u obligar a la entidad estatal contratante, procede a estipular, junto con la compañía aseguradora, los términos del contrato de seguro de cumplimiento a favor de la aludida entidad estatal contratante a la cual le corresponde la condición de asegurada. 
"En ese sentido cabe señalar entonces que cuando la entidad estatal contratante, en su condición de asegurada, aprueba los términos del contrato de seguros que se ha estipulado a su favor sin que mediare poder para representarla y que ha sido sometido a su revisión, naturalmente está manifestando su aceptación o consentimiento en relación con dicha estipulación y, por tanto, a partir de ese momento sólo esa entidad estatal podrá demandar o exigir el cumplimiento del mismo."

La particular importancia que se da en esta sentencia a la aprobación que la entidad estatal debe dar a la garantía conforme a lo que dispone hoy y desde hace mucho tiempo el Estatuto de Contratación Administrativa, viene siendo relevada también en algunos salvamentos de voto; dentro de este orden de ideas, ese acto de aprobación es indispensable para la existencia del contrato y, siendo así, con mucho más razón es imposible negar a la entidad pública en este caso la condición de parte contractual ${ }^{3}$.

b) El contrato de seguro de cumplimiento de contratos estatales, así no sea un contrato estatal en sí mismo, es accesorio a un contrato estatal y debe seguir su suerte en términos de jurisdicción aplicable. Esta tesis fue sostenida particularmente en vigencia del artículo 70 del decreto 222 de 1983 que señalaba que el seguro de cumplimiento de contratos estatales forma parte del contrato garantizado; no obstante también fue sostenida posteriormente. Ver a este respecto, auto de octubre 20 de 2005, Consejo de Estado. Sala Contencioso Administrativo. Sección Tercera. Ponente: Doctora María Elena GIRALDO. Expediente 300124.

c) El proceso ejecutivo que se adelanta con base en seguros de cumplimiento de contratos estatales, debe ser conocido por la jurisdicción contenciosa administrativa por razón de lo que se conoce como "jurisdicción por atracción".

d) La integración del título ejecutivo en estos casos se logra con la inclusión del contrato estatal garantizado, lo cual determina que el conocimiento del proceso pertenece a esta jurisdicción. Ver a este respecto: Auto de 5 de noviembre de 2003. Consejo de Estado. Sala Contencioso Administrativo. Sección Tercera. Ponente: Doctora MaríA Elena Giraldo. Expediente: 24818.

No obstante, aún quienes discrepan de la tesis anterior, concuerdan en que es la justicia ordinaria la que debe conocer del proceso ejecutivo cuando el ejecutivo se adelanta conjuntamente contra el asegurador y el contratista afianzado y cuando se trata de seguros de cumplimiento celebrados respecto de contratos celebrados por entidades públicas que no están sujetos a las normas del Estatuto de Contratación Administra-

3 Sección III del Consejo de Estado. Salvamento de voto a la sentencia de 19 de febrero de 2009, expediente 24609.

$4 \quad$ En el mismo sentido: Auto 1999, agosto 12, exp. 16124; Auto 2000, agosto 03 exp. 14368; Auto 2003, febrero 27, Exp. 23497; Auto 2003, noviembre 20, exp. 19929. 
tiva. (Ver: auto de 2009 junio 01. Consejo de Estado. Sala Contencioso Administrativo. Sección Tercera. Consejero Ponente. Ramiro SaAvedra BeCERra. Expediente 35731 :

"Situación que cambió con la entrada en vigencia de la Ley 1107 de 2006, por medio de la cual modificó el artículo 82 del C.C.A., y así, quedó definido de manera concreta, el objeto de la jurisdicción de lo contencioso administrativo,... Las modificaciones introducidas mediante la norma transcrita, tienen que ver con los siguientes aspectos: de un lado se definió que el objeto de la Jurisdicción de lo Contencioso Administrativo consiste en "juzgar las controversias y litigios originados en la actividad de las entidades públicas" en lugar de "juzgar las controversias y litigios administrativos", como disponía el artículo modificado. De otro lado, incluyó, en forma expresa, a las sociedades de economía mixta, siempre que el capital estatal sea superior al 50 por ciento. Ahora bien, tratándose de contratos celebrados por establecimientos de crédito de carácter estatal, el artículo 32 de la Ley 80 de 1993 establece que los contratos celebrados por éstas dentro del giro ordinario de sus negocios no están sujetos a las disposiciones del Estatuto General de Contratación Estatal, esto es, a la Ley 80 de 1993, por lo que no es posible aplicarles el contenido del artículo 75 ibídem, única disposición que le otorga competencia a esta Jurisdicción para conocer de los procesos de ejecución derivados de contratos estatales. En consideración a lo anterior, el Despacho advierte que esta jurisdicción no tiene competencia para conocer de los procesos que correspondan al giro ordinario de las actividades propias del objeto social de las entidades estatales, puesto que éstos no están sujetos a la norma de competencia prevista en referido artículo 75, la cual, como se anotó, se sigue aplicando aún en vigencia de la Ley 1107 de 2006.

No obstante, recientemente se abre paso hoy un argumento definitivo, basado en la Ley 1107 de 2006: En sentencia de nueve (9) de agosto del año pasado, con ponencia del Dr. MAURICIO FAJARDO dentro del expediente 21432, el Consejo abandonó la argumentación utilizada en sentencia del mismo mes que se menciona en el anterior literal a) para adoptar la posición expuesta al respecto en algunas aclaraciones formuladas por magistrados de la misma sección a este respecto. Dijo la Sección III del Consejo de Estado, en esta oportunidad, refiriéndose al alcance de la ley mencionada:

“Respecto de su alcance se pronunció la Sala mediante auto de febrero 8 de 2007, radicación 30.903, en el cual, a propósito de los asuntos que interesan al caso que aquí se examina, señaló:

"A manera de síntesis, puede resumirse la nueva estructura de competencias de la jurisdicción de lo contencioso administrativo, con la entrada en vigencia de la ley 1.107 de 2006, de la siguiente manera:

“i) Debe conocer de las controversias y litigios precontractuales y contractuales en los que intervenga una entidad pública, sin importar su naturaleza, ni el régimen jurídico aplicable al contrato, ni el objeto del mismo." 
Como será mencionado más adelante, la Ley 1150 de 2007, no hizo ninguna claridad sobre este tema, sino que agregó un factor de confusión, toda vez que, si con fundamento en la doctrina del Consejo de Estado que ha sido reseñada, podíamos confiar en una cierta uniformidad de las decisiones que son de esperar a este respecto, el artículo 17 de la ley, al referirse al tema de las multas para zanjar definitivamente este otro espinoso asunto, resolvió hacer una confusa alusión a la jurisdicción coactiva, que viene a revivir todas las polémicas referentes al tema de la jurisdicción.

\subsection{Las defensas oponibles por parte del asegurador}

Este es un punto que trae al centro de la discusión el tema de la relación del contrato de seguro con la fianza, en la medida en que muchos aspiran a ver en el seguro de cumplimiento las características propias de la fianza como una forma de garantía que se considera generalmente particularmente eficaz y a toda prueba, sobre todo en la medida en que igualmente se considera, y es hasta cierto punto cierto, que las excepciones oponibles por el fiador al acreedor son muy escasas. Ello explica porqué ha proliferado la tesis de asimilación del seguro de cumplimiento a la fianza, el texto de los estatutos de contratación administrativa son a menudo ambiguos a este respecto, y viene siendo evidente la proliferación de normas expresas que establecen, respecto del seguro de cumplimiento de contratos estatales particularmente, excepciones a la regulación propia del contrato de seguro, tal como ha ocurrido con el tema de la mora en el pago de la prima y de la revocabilidad unilateral, y más recientemente con algunos elementos introducidos por el decreto 2848 de 2008 que veremos más adelante.

Sin embargo, sin entrar de lleno en las razones que nos llevan a pensar que se trata de dos negocios jurídicos contrastantes en muchos aspectos, debemos mostrarnos claramente partícipes de la tesis que sostiene que el seguro de cumplimiento es bien diferente de la fianza, que ciertamente está sometido a una regulación legal diversa que se encuentra en su mayor parte contenida en el Código de Comercio, lo que lo hace particularmente susceptible al principio que hemos dado en llamar "de la comunicabilidad de las excepciones" consagrado en el artículo 1.044 del Código de Comercio, que permite al asegurador oponer al asegurado las mismas excepciones que hubiere podido oponer al tomador del seguro quien, siendo como es usualmente entre nosotros, el mismo afianzado, es persona muy diferente y además, contraparte contractual del asegurado mismo. Esta circunstancia marca una diferencia fundamental con la fianza, que no está definida en el Código Civil donde encontramos su regulación, como un contrato, sino como una obligación accesoria que puede llegar a constituirse por contrato pero que no necesariamente tiene fuente contractual, ya que, el fiador solo está en capacidad de oponer al acreedor excepciones de carácter real y ellas son definidas por la misma norma como las excepciones propias de la obligación principal.

La regulación de la fianza en el Código Civil no mira en absoluto la relación que puede existir entre el fiador y el deudor y, desde luego, no habilita ninguna defensa del fiador contra el acreedor fundada en esa relación que generalmente no existe, 
ya que tradicionalmente la fianza como figura contractual se ha considerado que vincula es al acreedor con el fiador y solo cuando el deudor principal establece una relación con el fiador, para efectos de remunerarlo generalmente, lo que acontece es la celebración de un contrato diferente al de la fianza que generalmente se ubica en el campo del mandato ${ }^{5}$.

En este punto estriba, no solamente una de las diferencias fundamentales entre el seguro y la fianza, sino uno de los motivos fundamentales de conflicto entre aseguradores y entidades estatales a la hora en que estas pretenden hacer efectivos sus derechos derivados de las pólizas de seguro.

Con estos antecedentes, claramente se observan los diversos problemas que ha presentado tradicionalmente la eficacia de las pólizas de seguro de cumplimiento como garantía de la contratación estatal. Por una parte, la asociación, para efectos de la determinación del momento de ocurrencia del siniestro y para efectos de la vía legal más característica y generalmente considerada por error como única, de hacer efectiva la póliza, de esta con un acto administrativo que debe además quedar ejecutoriado, lo cual hace depender la configuración del todo de lo que es generalmente un largo debate entre la entidad, su contratista y su asegurador, por la vía gubernativa. Y, por otra, la variedad de elementos de defensa que la regulación misma del contrato de seguro en general, implica para el asegurador dentro del contexto ya visto de que la garantía se vierte dentro de la estructura de un seguro de cumplimiento que no se sustrae en absoluto a esa regulación, salvo en años recientes (a partir del estatuto de 1993) en lo que se refiere a la falta de pago de la prima y a la revocabilidad del contrato.

Los jueces como una tendencia natural dada esta situación, y con ello me refiero fundamentalmente a la jurisprudencia del Consejo de Estado que debe desde luego marcar la pauta en este punto, han venido a consagrar unas doctrinas que son fundamentalmente cambiantes y contradictorias, muchas veces abiertamente contrarias a los dictados de la ley, para darles la mayor eficacia posible a las pólizas de cumplimiento en beneficio de las entidades públicas que no necesariamente tienen la razón en caso de conflicto.

Es ello, a mi modo de ver lo que explica lo que ha sido la tendencia general de esa jurisprudencia en los siguientes sentidos:

5 Dice a este respecto Camilo Muñoz Obando en su obra: La fianza. Imprenta Nacional, Bogotá, 1967, pág. 43: "Repárese ante todo, que el Título 35 cuyo estudio hacemos, no indica al fiador otros medios para libertarse que el de retractación consignado en el artículo 2365, ya visto, y el de relevo de que trata el artículo 2394, con la circunstancia especialísima de que esta última disposición no señala la falta de pago de la remuneración convenida entre las causas por las cuales puede pedir el relevo el fiador, no obstante que en el mandato si puede el mandatario desistir por esa causa de su encargo.

Dicho esto, cabe observar en cuanto a la resolución que las obligaciones mutuas no nacen del contrato de fianza, sino de otro distinto, el de mandato celebrado únicamente entre el fiador y el deudor. El acreedor permanece extraño a este contrato, en forma tal que su acción o derecho para que el fiador le pague, a falta del deudor, nada tiene que ver con él". 
1. Considerar generalmente, que las entidades estatales están facultadas para producir actos administrativos unilaterales en cualquier tiempo, mediante los cuales declaren ocurridos los siniestros que afectan las pólizas de cumplimiento, dando con ello a las aseguradoras un trato completamente diferente al que dan a sus contratistas, ante quienes sus facultades se encuentran claramente constreñidas a un número muy reducido y típico de actos que deben ser producidos en oportunidades igualmente muy definidas.

Ya se ha visto que a esa conclusión Ilega el Consejo de Estado sobre la base de reconocer la facultad de las entidades estatales para declarar indiscriminadamente la realización de los riesgos cubiertos por la póliza de cumplimiento, a través de actos administrativos en cualquier tiempo con la sola limitación referida a los diferentes alcances que sucesivamente se han dado al fenómeno de la prescripción de las acciones en esta materia y a lo que nos referiremos más adelante.

Por el contrario, la doctrina del Consejo de Estado se ha pronunciado repetidamente, antes y después de expedida la Ley 80 de 1993, para establecer la limitación temporal que tienen las entidades públicas, en cuanto la facultad de declarar la caducidad o el incumplimiento del contrato, limitación que como consecuencia de lo dicho antes no se aplica sino respecto del contratista mismo.

Varias sentencias del Consejo de Estado definieron claramente que la facultad de declarar unilateralmente la caducidad del contrato o el incumplimiento del mismo, así como su terminación por cualquier otra causa y la imposición de multas, quedaba limitada en el tiempo al lapso de duración del contrato $^{6}$ y que, antes de la vigencia de la Ley 80 de 1993, solo con posterioridad podía declararse el incumplimiento únicamente con el objeto de hacer efectiva la cláusula penal pecuniaria. Esta última posibilidad, antes descartada por la jurisprudencia del Consejo de Estado comenzó a admitirse con la sentencia de enero 29 de 1988, proferida por la Sección III con ponencia del Doctor Carlos Betancur Jaramillo dentro del expediente 3129 y tuvo su fundamento en lo dispuesto por el artículo 72 del decreto 222 de 1983, normas que establecía como obligatoria la cláusula penal pecuniaria y autorizaba a la contratante a hacerla efectiva en caso de declaratoria de caducidad o de incumplimiento. Esta doctrina posterior fue reiterada en sinnúmero de decisiones por lo cual puede considerársela particularmente consistente y confiable sobre el particular ${ }^{7}$.

$6 \quad$ Sentencia de mayo 6 de 1992, expediente 6661, ponente: Dr. Carlos Betancur Jaramillo. Sentencia de octubre 1o de 1992, expediente 6631, ponente: Dr. Carlos Betancur JarAmillo. Respecto de las multas, es particularmente clara la sentencia de octubre 30 de 1997, expediente 10874 con ponencia del Doctor Daniel Suárez Hernández. Igualmente sentencia de diciembre 10 de 1998, expediente 11446 con ponencia del Doctor Germán Rodríguez Villamizar.

7 Entre otras: Sentencia de Septiembre 13 de 1991. Expediente 5127. Ponente: Dr. Carlos Betancur Jaramillo; sentencia de octubre 10 de 1992 Expediente 6631. Ponente: Dr. Carlos Betancur Jaramillo; sentencia de septiembre 18 de 1997, expediente 11524. Ponente: Dr. Jesús María Carrillo. 
La doctrina anterior fue complementada luego con la precisión de que en todo caso esa declaratoria de incumplimiento aún para efectos de hacer efectiva la cláusula penal, no podía ser concebida después de vencido el término del que dispone la administración para liquidar el contrato, según sentencia ya citada de 30 de octubre de 1997 proferida con ponencia del Doctor Daniel SuÁrez HeRnÁndez dentro del expediente 10.874. Igualmente se precisó que la declaratoria unilateral de incumplimiento no es posible una vez que se ha producido la liquidación del contrato sin objeción de las partes, tal como consta en la sentencia de mayo 6 de 1992, proferida con ponencia del Doctor CarLos Betancur Jaramillo, dentro del expediente 6661.

Vale la pena anotar, sin embargo, que igualmente a este respecto el Consejo de Estado determinó en varias ocasiones que incluso la declaración de incumplimiento por acto administrativo unilateral no podía hacerse después de culminado el lapso de duración del contrato para los solos efectos de hacer efectiva la garantía de cumplimiento por parte del asegurador; en otras palabras, la jurisprudencia del Consejo determinó la improcedencia de la declaratoria de realización del riesgo de incumplimiento con posterioridad a ese término. Al respecto puede consultarse la sentencia de octubre 1 o de 1992, Consejero Ponente: CARLOS BetanCUR Jaramillo, demandante: Asinarco Ltda. Demandado: Alcaldía Municipal de Rionegro, expediente 6631.

Dice la sentencia a este respecto:

“... Podía hacerse esa declaración de incumplimiento, no con la finalidad señalada en el artículo 72 del decreto 222 de 1983 (la efectividad de la cláusula penal), sino, pura y simplemente, para hacer efectiva la garantía de cumplimiento pactada en el contrato? Estima la sala que no. Y su pensamiento ha sido no solo coherente sino reiterado. Durante la ejecución del contrato la declaración de incumplimiento solo puede hacerse para imponer multas o para declarar la caducidad del contrato, y vencido el plazo contractual únicamente para hacer efectiva la cláusula penal pecuniaria. Y esa misma jurisprudencia ha afirmado que si la administración estima que los perjuicios son mayores al valor de esa cláusula penal, no podrá decidirlo unilateralmente sino que tendrá que acudir al juez del contrato."

En igual sentido puede consultarse: Consejo de Estado, Sección Tercera, sentencia de noviembre 22 de 1989, exp. 5253, Actor: Seguros del Comercio, C.P. CARLos Betancur Jaramillo.

Pero del acto administrativo declaratorio del incumplimiento del contrato, dejó de hablarse con posterioridad a la expedición de la Ley 80 , dado que esta ley eliminó la cláusula penal pecuniaria como cláusula obligatoria en los contratos estatales ${ }^{8}$.

$8 \quad$ En sentencia de 18 de marzo de 2004, dentro del expediente 15936, publicada en Jurisprudencia y Doctrina, tomo XXXIII, No. 390, junio de 2004, págs. 860 y ss. se explica 
Pero la restricción temporal que la jurisprudencia contencioso administrativa tradicionalmente impone a las entidades estatales para declarar la caducidad, sigue vigente y aún, muy recientemente volvió a su tesis más severa, en el sentido de que la resolución correspondiente solo podrá proferirse mientras no haya vencido el término de duración del contrato y ni siquiera en consecuencia durante la etapa de su liquidación como con anterioridad lo aceptaba.

Este regreso a su tesis más restrictiva se observa en la sentencia de 20 de noviembre de 2008. Sección III. Consejera Ponente. Ruth Stella Correa Palacio. Expediente 17031, a la cual pertenecen los siguientes apartes:

"Las últimas posturas jurisprudenciales, han abordado el problema jurídico de la competencia temporal de las medidas sancionatorias desde la perspectiva de dos plazos definidos en el contrato: el plazo para ejecutar el contrato y el plazo para liquidarlo, lo que condujo a colegir que el contrato no se ha extinguido mientras subsistan obligaciones pendientes de cumplir y que expirado el plazo de ejecución la Administración puede exigir y evaluar su cumplimiento, definir si fue o no satisfactorio e imponer las sanciones previstas en la ley y en el contrato aún durante la etapa de la liquidación. No obstante, en esta oportunidad considera la Sala que existen elementos de reflexión que permiten reexaminar el límite temporal para la declaración de la caducidad del contrato estatal por parte de la Administración, según la diferenciación de los conceptos de plazo de ejecución y de plazo de liquidación del contrato, la finalidad, naturaleza y noción legal de la caducidad antes expuestas, así como su armonización en el contexto de la etapa de liquidación del contrato, conforme a la naturaleza de esta última operación... al examinar nuevamente los límites temporales de este poder exorbitante, la Sala concluye que la caducidad del contrato sólo puede declararse durante el plazo de ejecución y mientras se encuentre éste vigente, y no durante la etapa de la liquidación, teniendo en cuenta: en primer lugar, los elementos de su definición legal; en segundo lugar, la finalidad de protección del interés público de esta medida excepcional; en tercer lugar, que la etapa de liquidación del contrato no está concebida para la adopción de la caducidad del contrato; y en cuarto lugar, que el hecho de que se pueda recibir o aceptar en mora el cumplimiento de la obligación, no puede ser entendida como una extensión regular del plazo previsto en el contrato para ejecutarlo; es decir, porque: i.) Legalmente la caducidad sólo procede en caso de incumplimiento de las obligaciones del contratista "...que afecte de manera grave y directa la ejecución del contrato y evidencie que puede conducir a su paralización"... Se trata de un poder excepcional que le ha sido conferido a la Administración con la finalidad de afrontar el

parcialmente este hecho por la derogatoria de ciertas normas del decreto 222 de 1983 que fue remplazado por la Ley 80 de 1993. Todo ello para sostener la posibilidad, aún bajo la vigencia de la Ley 80 , de que se pacten cláusula penal y multas en los contratos estatales sujetos a ese estatuto. Decisión muy relacionada con: Auto de 4 de junio de 1998, expediente 13988 y sentencias de 13 de septiembre de 1999, expediente 10264 y de 3 de mayo de 2001, expediente 12724. 
incumplimiento del objeto contractual y garantizar así la prestación regular, continua y eficiente de los servicios públicos y funciones a cargo de la entidad contratante... El término o plazo concedido para la etapa de la liquidación unilateral o bilateral del contrato, no está destinado para la adopción de la caducidad del contrato..... La facultad que tiene el acreedor de recibir o aceptar tardíamente o en mora el cumplimiento de la prestación, no puede ser entendida como una extensión del plazo estipulado en el contrato para ejecutarlo y que autorice, por tanto, declarar su caducidad dentro del término que se tiene para liquidarlo."

En igual sentido pueden consultarse las sentencias de septiembre 13 de 1999, exp. 10264 y de marzo 15 de 2001, exp. 13352.

2.- Considerar que los títulos ejecutivos que se integran con las pólizas de seguro de cumplimiento de contratos estatales, no necesariamente deben contener obligaciones expresas, claras y actualmente exigibles a cargo de las compañías de seguro. Esta es una consecuencia de las consideraciones que ha hecho el Consejo de Estado en sentencias en las que ha avalado plenamente la posibilidad de que las entidades estatales demanden el pago de los valores asegurados señalados para las diferentes coberturas en las pólizas de seguro de cumplimiento, a lo que me referiré más adelante.

3.- Muy relacionado con el anterior, y una de las doctrinas a mi juicio más graves e inconvenientes que viene prohijando el Consejo de Estado en esta materia, que las entidades públicas frente a la cobertura básica de cumplimiento y a las demás coberturas características de la garantía única, pueden en el acta de liquidación del contrato o en otro acto administrativo complementario, señalar la cuantía de los perjuicios que pretenden haber sufrido como consecuencia del incumplimiento del contrato por parte del contratista y cobrar ese valor a las compañías de seguro.

También ha sido reiterada la doctrina que venía sentando el Consejo de Estado en el sentido de que las entidades estatales no estaban en capacidad, carecían de la facultad de autoseñalarse la cuantía de los perjuicios que hubieren podido sufrir como consecuencia del incumplimiento de sus contratistas.

Muchas providencias de la Corporación acreditan este aserto, que, por lo demás responde al simple hecho de que no existía norma alguna que concediera a las entidades una facultad tan excepcional y que se presta desde luego a toda clase de abusos ${ }^{9}$. En ese sentido, esta es una doctrina particularmente importante, porque obliga a las entidades contratantes en todos los casos a acudir al juez del contrato para hacer efectivas

$9 \quad$ Sentencia de 11 de diciembre de 1989. Sección III del Consejo de Estado. Consejero Ponente: Dr. Gustavo De Greiff Restrepo. Expediente: 5334. Informativo jurídico de Fasecolda. No. 80, páginas 14 y ss. También la sentencia ya citada para otros efectos de Octubre 1으 de 1992, con ponencia del Dr. Carlos Betancur Jaramillo en el expediente 6631 y la sentencia de noviembre 22 de 1989, dentro del expediente 5253 del mismo ponente. 
las pólizas de cumplimiento de contratos estatales en lo que se refiere a la garantía de cumplimiento propiamente dicha, cuando se trata de exigir el pago de los perjuicios derivados por el incumplimiento y no el pago de la cláusula penal o las multas.

Esta doctrina ha sido ratificada recientemente en dos decisiones que relaciono a continuación: sentencia de 22 de junio de 2000. Consejo de Estado. Sala Contencioso Administrativo. Sección Tercera. Consejera Ponente: Doctora María Elena Giraldo, Expediente 12723, a la cual corresponden los siguientes apartes:

"De otra parte, destaca la Sala que el acto de liquidación unilateral de un contrato que no contenía cláusula penal pecuniaria, para determinar las obligaciones a cargo del contratista, no podía aplicar sanciones distintas a lo acordado en el respectivo contrato. La Administración, en este caso, sólo podía deducir obligación del contratista teniendo en cuenta el valor de las sanciones por aplicar, de conformidad con lo acordado por el respectivo contrato y lo determinado en el acto de declaratoria de caducidad del mismo. Por consiguiente cuando la U.I.S., en un contrato celebrado en 1973 que no contaba con cláusula penal pecuniaria, liquidable sólo de conformidad con lo acordado por el respectivo contrato, liquidó otros perjuicios distintos a la sanción económica al contratista por incumplimiento parcial (multa) incurrió en incompetencia material. Por consiguiente, si en el contrato referido no se pactó cláusula penal pecuniaria, la Administración no tenía la facultad para liquidar, unilateralmente, a cargo del contratista otros perjuicios, distintos del incumplimiento parcial de éste. La U.I.S. debió acudir a la Jurisdicción de lo Contencioso Administrativo, juez de dicho contrato, y pretender la indemnización de los otros perjuicios causados por el contratista, no cubiertos por la cláusula de multas, que dieron lugar, precisamente, a dicha Universidad a declarar la caducidad administrativa del contrato."

Y más recientemente: sentencia de junio 18 de 2008. Consejo de Estado. Sala Contencioso Administrativo. Sección Tercera. Consejero Ponente: Doctor. MAuRICio FajaRDo Gómez. Expediente 29290. Por lo demás, en igual sentido se ha pronunciado la Corte Constitucional, en sentencia T-472 de 1996, M.P. Eduardo Cifuentes Muñoz.

Sin embargo, en la sentencia ya mencionada antes de fecha 9 de agosto de 2009 la Sala reiteró su posición respecto de la potestad con la cual cuenta la Administración Pública para declarar el siniestro derivado de la ejecución de los contratos estatales, a través de actos administrativos, en los siguientes términos:

"La Sala reitera el criterio que de años atrás ha consolidado en el sentido de que la Administración goza de la prerrogativa de declarar el siniestro derivado de la ejecución de los contratos estatales, de hacer efectiva la garantía que ha sido constituida a su favor, y en esta oportunidad precisa que tal prerrogativa conlleva la de cuantificar el perjuicio, aún después de la terminación del contrato, mediante la expedición de actos administrativos, los cuales están sujetos al control 
gubernativo y judicial, en consecuencia, podrán ser impugnados ante la propia Administración mediante la interposición de los recursos que la ley ha previsto para el efecto y por vía judicial mediante el ejercicio de la acción contractual.

“En relación con las prerrogativas que posee la Administración frente a las garantías contractuales, también resulta pertinente establecer, como lo ha señalado la jurisprudencia dé la Sala, que en materia de contratación estatal no aplica el procedimiento previsto en los artículos 1075 y 1077 del Código de Comercio, relativos a la reclamación por parte del asegurado y a la objeción que puede formularle el asegurador, toda vez que tal reclamación se suple a través de la expedición de un acto administrativo mediante el cual la Administración unilateralmente declara ocurrido el siniestro y ordena la efectividad de las garantía sin la aquiescencia del asegurador, decisión que puede ser impugnada por éste y también por el contratista, administrativa y judicialmente." (Subrayas del original).

4.- A falta de lo anterior, considerar que la entidad pública, no obstante ser el seguro de cumplimiento un seguro de daños, puede cobrar directamente al asegurador la totalidad del valor asegurado para cualquiera de las coberturas de la garantía única, sin pasar por la prueba judicial o extrajudicial del perjuicio efectivamente sufrido como consecuencia del incumplimiento.

Pueden señalarse como antecedentes jurisprudenciales en este sentido las siguientes providencias de la Sección III del Consejo de Estado: el auto de 12 de octubre de 2000, dentro del expediente 18604 con ponencia de la Doctora María ELENA GIRALDO, la sentencia de mayo 24 de 2001 dentro del expediente 13598 con ponencia del Doctor Ricardo Hoyos, y sobre todo la sentencia de 11 de diciembre de 2002, dentro del expediente 22511, con ponencia de la Doctora María ElEna Giraldo.

5.- Considerar que en materia de prescripción, las reglas que rigen para las acciones de la entidad pública contra el asegurador se rige por reglas bien diferentes a las que rigen para el contratista y resultan cada vez más amplias respecto del tiempo y de la oportunidad de las que dichas entidades disponen para ello.

Esta realidad será analizada más adelante cuando abordemos el tema de la prescripción.

6.- Considerar que los procesos ejecutivos que se hacen con base a las pólizas de seguro de cumplimiento pertenecen al género de ejecuciones que, de acuerdo con el Código de Procedimiento Civil se hacen con base en providencias ejecutoriadas, reguladas por el artículo 509 del mencionado Código, lo cual implica la práctica imposibilidad de interposición de excepciones de fondo por parte de los aseguradores en esa clase de procedimientos y es lo que obliga generalmente a proponer procesos ordinarios de nulidad contra los actos administrativos con los que se integran los títulos ejecutivos en este caso, con las consecuencias ya conocidas en términos de economía procesal. 
Esta es una doctrina ya generalmente reiterada por el Consejo de Estado sobre la cual también discrepamos sustancialmente, ya que a nuestro modo de ver no existe duda alguna en el sentido de que el artículo 509 del C. de P.C., se refiere a providencias judiciales y no de otro tipo.

\section{LA SITUACIÓN ACTUAL}

Particularmente con las reformas introducidas con la Ley 1150 de 2007 y el decreto 4828 de 2.008, se trata hoy de enderezar un sistema que, como se ha visto, solo ha podido desarrollarse a través de una jurisprudencia muy discutible, pero se ha hecho, a nuestra manera de ver, de manera confusa, contrariando la naturaleza del contrato de seguro y dejando gran cantidad de temas por discutir.

\section{Veamos:}

En primer lugar, la Ley 1150, introdujo en su artículo séptimo (7o) que es el que se refiere expresamente al tema de las garantías, solamente un elemento nuevo en punto a la eficacia de las pólizas de seguro, al establecer en su inciso 40 que "El acaecimiento del siniestro que amparan las garantías será comunicado por la entidad pública al respectivo asegurador mediante la notificación del acto administrativo que así lo declare".

La redacción de este inciso es muy defectuosa y, conforme a lo que se ha visto atrás, pareciera eliminar la idea de que el siniestro está constituido por el acto administrativo que lo declara, que ha sido la idea dominante en nuestro medio por muchos años, para darle a ese acto la simple función de "aviso de siniestro". Como se verá, el decreto 4828, vuelve sobre este punto, pero en forma igualmente defectuosa que, no dudo en afirmarlo, creará hacia el futuro muchas confusiones.

Por lo demás, se limitó a dejar a la reglamentación del Gobierno las condiciones generales, los criterios de exigencia, las clases y los niveles de amparo, así como la posibilidad de división de las garantías teniendo en cuenta las etapas del contrato garantizado y los riesgos a los que se halla sujeto, reiterando los principios de no revocabilidad unilateral de las pólizas y de no terminación automática de las mismas por falta de pago de la prima.

En su artículo 17, como ya se mencionó, la ley se ocupó del tema de la cláusula penal y las multas, para tratar de dejar en claro los dos temas que habían quedado planteados a partir de la vigencia de la Ley 80 de 1993 que eliminó estas cláusulas como cláusulas obligatorias en los contratos estatales. El primero era si frente a esa eliminación las cláusulas había desaparecido de la órbita de la contratación estatal o, si, por el contrario, podían seguir pactándose aunque ya no de manera obligatoria sino como simple parte del acuerdo de voluntades; el segundo, si, una vez pactadas, la misma entidad estatal podía imponerlas a través de un acto administrativo unilateral ya que este punto particularmente había dado lugar a sentencias contradictorias del Consejo de Estado. 
Como se sabe, el artículo 17 de la Ley 1150, estableció claramente la posibilidad de pactar este tipo de cláusulas en los contratos y, adicionalmente facultó expresamente hacia el futuro a las entidades estatales para imponerlas, tanto la cláusula penal como las multas en caso de haber sido pactadas, estableciendo de paso, la muy discutible solución de que, respecto de contratos celebrados con anterioridad a la vigencia de la ley, esa facultad debía considerarse existente siempre y cuando el contrato hubiese previsto que la entidad estatal pudiera proceder de esa manera.

Pero no solamente la ley se refiere a la posibilidad de las entidades estatales de imponer este tipo de sanciones, sino a la de hacerlas efectivas por diferentes medios, entre ellos el cobro de la garantía, "....incluyendo el de la jurisdicción coactiva". Esta mención de pasada a la jurisdicción coactiva, como hemos dicho antes, revive otra vez todo el tema de la jurisdicción aplicable, pues, cómo debe entenderse esta mención: a) ¿como el establecimiento de la jurisdicción coactiva, en general para la acción ejecutiva que deriva de las pólizas de seguro de cumplimiento de contratos estatales ?, b) ìlo anterior de manera exclusiva o sin eliminar la posibilidad de acceso a la jurisdicción contenciosa con base en los criterios expuestos por el Consejo de Estado ?; c) ila jurisdicción coactiva solamente para el cobro de las multas al contratista?; d) ¿La jurisdicción coactiva, siempre y cuando exista esa posibilidad con base en normas generales? Es francamente desconcertante que un tema general, de tanta trascendencia se haya dejado a una anotación imprecisa y a la carrera respecto de una cuestión particular con un objeto muy diferente al de la fijación de temas procesales.

La discusión respecto a la facultad de imposición de multas antes de la vigencia de la ley 1150, se analiza a espacio en la sentencia de la Sección III de julio 30 de 2008, expediente 21574, con ponencia del Doctor EnRIQUe GiL Botero, y salvamento de voto del Doctor Ramiro SAAVEDRA.

El decreto 4828, mediante el cual “...se expide el régimen de garantías en la contratación de la administración pública", introduce las siguientes novedades en lo que hace relación a la eficacia de las mismas, cuando se trata de pólizas expedidas por las compañías de seguro:

a) Establece que, en los eventos de caducidad con o sin cláusula penal y multas, el acto administrativo que la declara "constituye el siniestro" en las garantías otorgadas mediante póliza de seguro.

b) Establece que en el evento de los demás casos de incumplimiento, esto es, en lo referente a las coberturas de incumplimiento, buen manejo y correcta inversión del anticipo o pago anticipado, pago de salarios, prestaciones sociales e indemnizaciones laborales, estabilidad de la obra, calidad y correcto funcionamiento de los bienes y equipos suministrados y calidad del servicio, el acto administrativo correspondiente “...constituye la reclamación" en las garantías otorgadas mediante póliza de seguro.

Al establecer estas dos disposiciones diferentes, respecto de las también diferentes coberturas que puede involucrar la garantía única, el decreto, como se 
advirtió antes, crea una nueva confusión, porque no es lo mismo decir que el acto administrativo constituye el siniestro a decir que constituye la reclamación de la indemnización a cargo del asegurador. Por lo demás, si en algo ha sido constante, como se sabe la jurisprudencia del Consejo de Estado y esta vez con toda razón, es en sostener que en el caso de las pólizas de seguro de cumplimiento de contratos estatales no es necesario, como en el caso de las demás pólizas de seguro, una reclamación, sea ella judicial o extrajudicial por parte del asegurado, en este caso la entidad pública. El momento de la ocurrencia del siniestro es vital para establecer, entre otras cosas el término de prescripción o caducidad para el cobro y la manera como las entidades deben hacer efectivas las pólizas y ciertamente decir que el acto administrativo constituye la reclamación en el caso de la mayoría de las coberturas de la póliza, deja en el aire este tema de la ocurrencia del siniestro.

Esta disposición establece que las entidades públicas procederán a proferir, pues, tres tipos diferentes de actos administrativos que constituirán a su vez, en todos los casos si hacemos caso omiso de la contradicción de los términos que se utilizan, los correspondientes siniestros respecto de las pólizas de cumplimiento: la declaración de caducidad, la imposición de multas (y cláusula penal) y el incumplimiento del contrato. Ya no habla aquí estrictamente, de declarar la ocurrencia del siniestro de declarar el incumplimiento, lo cual a nuestro juicio va a plantear nuevamente la polémica en torno a la facultad de declaratoria de incumplimiento del contrato como figura diferente a la de caducidad, que no está prevista en el estatuto de contratación estatal y que crea este decreto reglamentario, exclusivamente para efectos de hacer efectiva la garantía de cumplimiento.

El tema de la imposición de multas se aclara en el artículo 17 de la ley, en el sentido de que se atribuye expresamente a las entidades estatales la facultad de imponerlas unilateralmente para lo cual forzosamente deberá declarar que existe un incumplimiento de parte del contratista a cualquiera de sus obligaciones, conforme a lo pactado al respecto, pero es notorio que cuando se trata de hacer efectiva la garantía en este punto, no se alude expresamente a la oportunidad que la entidad tiene para hacerlo, lo cual nuevamente plantea este interrogante; ¿será en este caso una oportunidad diferente a la que tiene frente al contratista?

c) Permite finalmente, de manera expresa que la entidad administrativa en el mismo acto, proceda a "cuantificar el monto de la pérdida", con todas las consecuencias que de allí se derivarán.

Esta es una facultad que, como se ha visto, ha sido negada sistemáticamente por la doctrina del Consejo de Estado hasta la fecha de entrada en vigencia de la ley, supone no solo un tratamiento diferencial inexplicable e injustificable entre el contratista y el asegurador, y la práctica enseña que es algo que se presta a múltiples arbitrariedades, en la medida en que ni siquiera se exige la prueba, sino la simple cuantificación de los perjuicios, y a discusiones inacabables que van a recargar seguramente aún más a la administración de justicia. 
d) Al referirse en su artículo 15 concretamente a la regulación de las pólizas de seguro, el decreto 4828, establece lo que llama un mínimo de condiciones generales:

1.- El valor de las diferentes coberturas no es acumulable y son excluyentes entre sí.

2.- Solamente admitirá las siguientes exclusiones: causa extraña, daños causados por el contratista a los bienes de la asegurada no destinados al contrato, uso indebido o inadecuado o falta de mantenimiento preventivo a que esté obligada la contratante y el demérito o deterioro normal que sufran los bienes entregados con ocasión del contrato, como consecuencia del simple transcurso del tiempo. Advierte a este respecto que cualquier estipulación en contrario no producirá efecto alguno, lo cual, como se sabe, en términos del Código de Comercio implica que en ese caso la cláusula será ineficaz de pleno derecho.

Se observa claramente que estas no son exclusiones del riesgo, sino eventos de pérdida que no corresponden a la realización del riesgo. Exclusiones podrían ser, incumplimientos del contratista debidos a causas específicas que la aseguradora se abstiene de cubrir, como ocurrió por ejemplo con el caso de los incumplimientos que podían derivarse de fallas informáticas o errores en los equipos electrónicos del contratista, que fueron generalmente excluidas en estas pólizas particularmente cuando se avecinaba el año 2000; o cierto tipo de pérdidas derivadas del incumplimiento que igualmente las aseguradoras pueden abstenerse de cubrir, por ejemplo las derivadas de daños morales o de lucro cesante que, a diferencia de lo que pasa con las pólizas de responsabilidad civil, si podrían ser excluidas de la cobertura aunque las compañías no acostumbran hacerlo, pero que puede ser un motivo de atención hoy, cuando el Consejo de Estado a contemplado ya la posibilidad de que existan perjuicios morales para personas jurídicas, derivados del incumplimiento de contratos. Sentencia de 2008 noviembre 20. Consejo de Estado. Sala Contencioso Administrativo. Sección Tercera. Consejera Ponente. Ruth Stella Correa Palacio. Expediente $17031^{10}$.

Podría preguntarse, cuál es el sentido de prohibir en este caso la facultad de selección de riesgos con la que cuenta tradicionalmente el asegurador frente al contrato de seguro. ¿Puede desnaturalizarse de esa manera el contrato solamente por el hecho de que el asegurado en este caso es una entidad estatal? Si bien es cierto que las aseguradoras pueden incurrir en abusos en el señalamiento de exclusiones y que muchas veces hacen figurar como tales ciertos eventos que no lo son o que no se compadecen con la realidad del riesgo o con lo que ha dado en llamarse la "reciprocidad esencial" del contrato, no es menos cierto que basta observar las pólizas actualmente en el mercado para constatar que las mismas no suelen incluir exclusiones o se refieren a unas muy limitadas que son por lo general inútiles pues se

10 Providencias en igual sentido: Consejo de Estado, Sección Tercera, sentencias de agosto 20 de 1993, exp. 7881; abril 13 de 2000, exp. 13342; julio 10 de 1997, exp. 10229; noviembre 13 de 2008, exp. 14584. Corte Constitucional, sentencias T-133 de 1995; T-094 de 2000, M.P. Dr. Álvaro Tafur; T-938 de 2001, M.P. Dr. Eduardo Montealegre; T-472 de 1996; T-412 de 1992. 
refieren a hechos, que, como en el caso de la ley, no son verdaderas exclusiones sino ausencia de riesgo. Pero, por otra parte, bien pueden sobrevenir circunstancias que justifiquen plenamente el establecimiento de cierto tipo de exclusiones, caso en el cual no tiene lógica ninguna privar a las aseguradoras de la posibilidad de pactarlas con adecuado conocimiento del asegurado.

3.- No podrá incluirse en el contrato la llamada "cláusula de proporcionalidad". Con la misma advertencia anterior en lo que se refiere a las cláusulas incluidas en contrario.

4.- Debe incluir la condición de que el afianzado aceptará, dado el caso, la cesión del contrato en los eventos en que el asegurador, con anuencia de la compañía de seguros, resuelva cumplir con sus obligaciones continuando con la ejecución del contrato.

5.- Reitera los principios ya consagrados desde la Ley 80 de 1993, acerca de la no terminación automática del contrato por mora en el pago de la prima e irrevocabilidad de la misma, en forma unilateral.

6.- Para evitar las consecuencias de la aplicación del artículo 1.044 del Código de Comercio, obliga también a incluir dentro de las condiciones generales de la póliza, el efecto de inoponibilidad por parte del asegurador a la entidad pública asegurada, de las excepciones provenientes de la conducta del tomador.

Esta excepción a lo que se ha llamado el principio de la comunicabilidad de las excepciones, se enfrenta a un problema que es el que plantea el artículo 1.041 del C. de Co., en la medida en que él mismo señala como las obligaciones (y debe entenderse que también las cargas) que pesan sobre la parte asegurada deberán ser cumplidas, por quien esté en capacidad de hacerlo, sea el tomador, el asegurado o el beneficiario. Entonces, si bien las excepciones derivadas de la conducta del tomador no son oponibles al asegurado, iqué pasa con aquellas que son atribuibles jurídicamente indistintamente a la conducta de ambos? Para hacer eficaz esta inoponibilidad de excepciones, deberá sin duda alguna establecerse una excepción a lo que se ha llamado la regla de fungibilidad de las obligaciones y de las cargas en el contrato de seguro.

Pero además, también cabe preguntarse en este caso, si desde el punto de vista teórico y de la filosofía que inspira la tipicidad de los contratos, resulta razonable sustraer todo un ramo del seguro (ya que la tendencia general será a dotar de estas mismas características al contrato de seguro de cumplimiento de contratos entre particulares) a un principio establecido legalmente, que si bien contempla la posibilidad de derogaciones, sean legales o contractuales, deben ser por definición excepcionales. No estaremos en este caso frente a una nueva desnaturalización del contrato de seguro. 


\section{LA PRESCRIPCIÓN DE LA ACCIÓN DEL ASEGURADO CONTRA EL ASEGURADOR DERIVADA DEL CONTRATO DE SEGURO DE CUMPLIMIENTO DE CONTRATOS ESTATALES}

El tema de la prescripción de la acción para el cobro del seguro de cumplimiento ha seguido igualmente derroteros muy arbitrarios en la jurisprudencia del Consejo de Estado, ante la falta de normas expresas que regulen la prescripción de las acciones que derivan de este seguro en particular. La discusión comenzó desde luego en primer lugar por el criterio que debía seguirse en cuanto a las normas aplicables a este respecto; debía aplicarse el artículo 1.081 del Código de Comercio que regula en general la prescripción de las acciones y derechos que derivan del contrato de seguro y de las normas que lo rigen, o debían aplicarse normas sobre prescripción extintiva en general consagradas en el Código Civil, o normas especiales relativas a la prescripción de las acciones que se adelantan ante la Jurisdicción Contencioso Administrativa.

El Consejo de Estado, en medio de un sinnúmero de contradicciones referentes a la calificación que debía darse a este tema, si como de prescripción o de caducidad, optó inicialmente por adoptar la tesis de la aplicación de las normas generales sobre prescripción extintiva que se encuentran en el Código Civil y particularmente, como la efectividad de la póliza de seguro de cumplimiento se verificaba normalmente a través del proceso ejecutivo, la consagrada en el artículo 2536 que se refería precisamente al término de prescripción de la acción ejecutiva, lo que favorecía ampliamente a las entidades públicas dado el amplio término que esta norma contempla para estos efectos.

A partir de la expedición de la norma que consagraba en el Código Contencioso Administrativo el término al vencimiento del cual perdían los actos administrativos su fuerza ejecutoria (art. 66 del C.C.A.), el Consejo de Estado quiso aplicar esta norma para establecer el término de prescripción de la acción para hacer efectiva la póliza de cumplimiento de contratos estatales, una tesis igualmente favorable para las entidades públicas porque implicaba que no existía un término para ellas dentro del cual debían proferir los actos administrativos mediante los cuales integraban con la póliza de seguro del título ejecutivo, y solo las afectaba ese término de cinco años al término del cual el acto perdía su fuerza ejecutoria, el cual se contaba a partir de la ejecutoria del acto.

Estas dos tesis suponían ambas, que estaba en principio descartada totalmente la aplicación del artículo 1.081 del Código de Comercio que, ya se sabe, consagra los términos de prescripción de las acciones que derivan del contrato de seguro.

Posteriormente, durante muchos años, se consagró una doctrina ecléctica que mezclaba, a mi manera de ver sin ningún fundamento el artículo 1.081 del Código de Comercio con el artículo del Código Contencioso Administrativo, estableciendo que, a partir del momento en que la entidad pública tenía conocimiento del incumplimiento de su contratista, disponía de dos años (se hacía aquí alusión 
al término de prescripción ordinaria del artículo 1.081 del C. de Co.) para proferir (y generalmente para obtener la ejecutoria del acto administrativo con el cual se integraba el título) y, a partir de ese momento ya solo debía tenerse en cuenta el término previsto en el C.C.A. al vencimiento del cual el acto administrativo podía eventualmente perder su fuerza ejecutoria.

Esta doctrina, carece de todo fundamento, en la medida en que lo que el artículo 1.081 del C. de Co., prevé, es que el titular de la acción debe ejercerla dentro de los dos años siguientes al conocimiento que tenga de la ocurrencia del siniestro, y es obvio que la expedición de un acto administrativo unilateral por parte de la entidad pública no cumple esa función; al fin y al cabo la entidad pública también se ve obligada a emprender eventualmente una acción judicial para hacer efectivos sus derechos, en ese sentido su acto unilateral, por más acto administrativo que sea, solamente puede cumplir los efectos de una reclamación igualmente unilateral, si bien dotada de las cualidades de un acto de este tipo. Por lo demás, si se ha insistido tanto en que el siniestro ocurre con la expedición del acto administrativo y no con el hecho mismo de incumplimiento, con mayor razón resulta ilógica la aplicación de esta tesis, puesto que estrictamente no hay siniestro mientras no haya acto administrativo y en consecuencia la obligación del asegurador no sería exigible, lo que equivale en últimas a decir que podría llegar a extinguirse por prescripción una obligación que todavía no es exigible. En ese sentido, considero que no es posible afirmar que de esta manera se aplica o da cumplimiento al artículo 1.081 del Código de Comercio y viene a tratarse realmente de una interpretación inadecuada de esa norma. Si de aplicar el artículo 1.081 del C. de Co. se tratara, la apreciación correcta sería que la entidad pública dispone de dos años para ejercer su acción judicial, cualquiera que ella sea, a partir del momento en que tenga conocimiento del siniestro, esto es, a partir del momento en que tenga conocimiento del incumplimiento de su contratista (prescripción ordinaria), y de cinco años, a partir del momento en que objetivamente ocurre ese incumplimiento; esto implicaría que las entidades públicas tendrían que proceder con celeridad y diligencia a lograr la ejecutoria del acto administrativo con el que deben integrar la póliza de seguro para integrar un título ejecutivo que habilite para ellas la vía ejecutiva, o, si no están en capacidad de hacerlo, acudir directamente a la vía ordinaria, que, como se ha visto, a nuestra manera de ver está siempre abierta para las entidades estatales. Si llegare a considerarse que es aplicable en este caso el texto corriente de este tipo de pólizas en el sentido de que el siniestro se entiende ocurrido con la ejecutoria del acto administrativo, el primer término señalado, el de la prescripción ordinaria, comenzaría a contar desde ese momento. Pero en este caso lo que queda por establecer es el tiempo del cual dispone la entidad estatal para expedir ese acto administrativo y aquí es donde surge el problema que plantea la doctrina del Consejo de Estado según la cual ese tiempo es cualquier tiempo y no se encuentra limitado dentro de los términos de oportunidad que se predican de las resoluciones de caducidad o de incumplimiento del contrato estatal.

Desde ese punto de vista, el artículo 66 del C.C., relativo a la fuerza ejecutoria de los actos administrativos no tendría función alguna que cumplir, porque el 
título ejecutivo no está constituido por el acto administrativo, cosa que se olvida generalmente, sino por la póliza de seguro complementada o integrada con el acto administrativo, el cual, para estos efectos solo cumple el papel de un documento complementario, como requisito formal para conformar el título; a este respecto es claro el texto del artículo 68 del C.C.A. en sus numerales $4^{\circ}$ y $5^{\circ} \stackrel{\circ}{ }$, en el sentido de que prestarán mérito ejecutivo, entre otros, las pólizas de seguro de cumplimiento expedidas a favor de las entidades públicas.

Es por ello que resulta una mejora significativa en la doctrina del Consejo de Estado a este respecto, la doctrina que viene sentando últimamente y que ha sido ratificada en la sentencia ya comentada de 19 de febrero de 2.009 con ponencia del Doctor Mauricio Fajardo Gómez ${ }^{11}$, en la cual se desiste de acudir al artículo 66 del C.C.A. para establecer el término del cual dispone la administración para iniciar la acción ejecutiva, una vez expedido el acto administrativo que declara la ocurrencia del siniestro, para aplicar el término de caducidad de la acción contractual de dos años establecido por el artículo 136 del mismo estatuto. Al tomar esta posición, el Consejo de Estado, señala que lo dispuesto por el artículo 66 del C.C.A. no es un término de caducidad de la acción para ejecutar lo dispuesto en un acto administrativo, sino un término de exigibilidad o, diría más bien, de eficacia o validez del acto administrativo, que desde luego puede oponerse como defensa dentro del proceso que adelante extemporáneamente la entidad estatal, pero que no tendría las características propias de un término de caducidad: no se podría declarar de oficio por el juez, no se perderían los efectos interruptivos de la presentación de la demanda en caso de no cumplirse los presupuestos del artículo 90 del C. de P.C., etc. A esta sentencia corresponden los siguientes apartes:

“En este orden de ideas, se tiene entonces que la pérdida de fuerza ejecutoria a que se refiere el artículo 66 del Código Contencioso Administrativo, cuando han transcurrido 5 años sin que la Administración hubiere realizado los actos que le correspondan para ejecutar un determinado acto administrativo, no constituye un nuevo término de caducidad de la acción, pues el mismo se refiere a los efectos del acto administrativo que un caso como este constituye el título ejecutivo, asunto que atañe a uno de los requisitos para constituir dicho título puesto que relación con la exigibilidad del mismo, circunstancia que debe ser analizada por el juzgador al momento de dictar mandamiento de pago y de ordenar seguir adelante con la ejecución, en ejercicio de la facultad que le asiste para declarar excepciones de oficio."

Con esta variante, el Consejo de Estado sigue sosteniendo como tesis la combinación de los artículos 1.081 del Código de Comercio y 136 del C.C.A., para establecer el término de caducidad o prescripción de la acción de las entidades estatales para el cobro de las indemnizaciones derivadas del seguro de cumplimiento, precisando que

11 Radicación No. 2000-01720. Extractos: Revista Jurisprudencia y Doctrina, tomo XXXIX, No. 2010, enero de 2010, pág. 93 y ss. 
tienen dos años para expedir el acto administrativo, a partir del momento en que tienen conocimiento del incumplimiento del contratista, y dos años a partir del momento en que ese acto queda ejecutoriado para adelantar la acción contractual a la que se refiere el numeral 10 del artículo 136 del C.C.A. Lo anterior, con la aclaración de que los dos años con los que cuenta la administración, a partir del momento en que tiene conocimiento del incumplimiento del contratista, son dos años para expedir el acto simplemente sin necesidad de que ese acto quede ejecutoriado dentro del mismo término, y que ello implica que el acto puede ser expedido por fuera del término de vigencia del contrato de seguro, lo cual dirime por el momento la discusión que venía existiendo respecto de estos dos puntos, pues, como se sabe, en providencias anteriores el Consejo había sostenido algunas veces que el acto debía quedar ejecutoriado dentro del término de dos años y existía una alegación frecuente de las compañías de seguro, en el sentido de que el acto además debía ser expedido dentro del término de vigencia de la póliza; lo anterior es consecuencia desde luego del empeño por afirmar que el siniestro está constituido por el acto administrativo, lo que da pie, en sana lógica para hacer esta consideración.

La sentencia de 19 de agosto de 2009, con ponencia del Doctor MAURICIO FAJARDO Gómez $^{12}$, desarrolla de esta manera esa posición, citando una providencia anterior ${ }^{13}$ :

"Expuso el actor en su demanda que las Resoluciones números 20001200000013 del 19 de febrero de 1999 y 20001200-000030 del 23 de marzo de 1999, por medio de las cuales se declararon y confirmaron los siniestros de incumplimiento y de buen manejo e inversión del anticipo, fueron proferidas por TELECOM cuando carecí a de competencia para ello, por cuanto el término de ejecución del contrato se encontraba vencido. Se impone precisar entonces la época dentro de la cual la Administración Pública está facultada para expedir el acto administrativo por medio del cual declara la ocurrencia del siniestro, para lo cual, por su pertinencia, se citará in extensum la sentencia proferida por esta Sección el 22 de abril de 2009, con ponencia de la señora magistrada MiRYAM Guerrero de Escobar:

"Cabe precisar que la declaratoria del siniestro, materializada mediante un acto administrativo, deberá hacerse por la Administración, a más tardar dentro de los dos años siguientes a la fecha en que tenga conocimiento de la ocurrencia del siniestro, hecho que necesariamente debe acaecer durante la vigencia del seguro, así la declaratoria se produzca después de su vencimiento. Lo anterior tiene sustento tanto en la ley, artículo 1081 del Código de Comercio, como en la doctrina y la jurisprudencia que sobre el tema, en particular, ha desarrollado la Sala de Casación Civil de la Corte Suprema de Justicia y el Consejo de Estado.

12 Expediente 21432.

13 Sentencia de 22 de abril de 2009. Ponente: Doctora Miryam Guerrero de Escobar. Expediente: 14667. 
“El artículo 1081 del Código de Comercio consagró un término de dos años para la prescripción ordinaria y uno de cinco años para la extraordinaria, la primera de ellas corre desde el momento en que el interesado haya tenido conocimiento real o presunto del hecho que da base a la acción, (factor subjetivo) mientras que la extraordinaria por ser objetiva, correrá contra toda clase de personas sin consideración alguna del citado conocimiento, desde el momento en que nace el respectivo derecho.

“De otra parte ha señalado la doctrina que los términos de prescripción ordinaria y extraordinaria corren simultáneamente, es decir, que dentro del plazo de los cinco años puede operar el término de los dos años, lo cual no significa que el interesado pueda acogerse indistintamente, a su conveniencia, a una u otra de las prescripciones anotadas, toda vez que aquella que primero se agote está llamada a producir el efecto extintivo de la obligación o del derecho correlativo.

"A su vez, el Consejo de Estado, en sentencia de 6 de octubre de 2005, reiteró el criterio que de tiempo atrás había sostenido en relación con el término del cual disponía la Administración para declarar el siniestro acaecido en un contrato estatal amparado por un contrato de seguro. En el siguiente sentido se pronunció:

'El acaecimiento del siniestro, o sea, el incumplimiento, debe ocurrir dentro del plazo de vigencia del seguro fijado en la póliza, para que el Asegurador resulte obligado a la indemnización. Empero, dicho término no es el mismo dentro del cual las autoridades aduaneras deben declarar el incumplimiento. La Sala siguiendo este mismo criterio, se ha pronunciado reiteradamente en los siguientes términos:

'Cosa distinta la constituye el término para proferir el acto administrativo que ordene hacer efectiva la garantía, que junto con la póliza otorgada constituyen el título ejecutivo conforme lo preceptúa el artículo 68 numeral 5o. del Código Contencioso Administrativo.

'Término que contrariamente a lo expresado por el a-quo no necesariamente debe coincidir con el de vigencia de la póliza de garantía, porque éste tiene por objeto amparar el riesgo (incumplimiento) que se produzca en su vigencia. Ocurrencia que puede tener lugar en cualquier momento incluido el último instante del último día de vigencia. Hecho muy diferente al de reclamación del pago o a la declaratoria del siniestro ocurrido, que pueden ser coetáneos o posteriores a la de la vigencia de la póliza.

'Por regla general, la Administración dispone del término de (2) dos años para declarar el siniestro y la consiguiente efectividad de la garantía, contados a partir de cuando tenga conocimiento de la ocurrencia del siniestro, o de la fecha en que razonablemente podía tenerlo, conforme a lo dispuesto en el artículo 1081 del Código de Comercio, que establece los términos de prescripción en el contrato de seguros, a este tenor". 
“De lo anteriormente expuesto se colige que la Administración tiene como término máximo para declarar el siniestro, el de dos años después de haber tenido conocimiento de la ocurrencia de los hechos constitutivos del mismo, de tal suerte que expedido el acto administrativo que lo declara y ejecutoriado el mismo, mediante el agotamiento de la vía gubernativa, empezará a correr el término de los dos años que la ley ha previsto para el ejercicio de la acción contractual. Lo anterior no significa que el acto administrativo que declara el siniestro deba encontrarse en firme dentro de los dos años siguientes al conocimiento del hecho por parte de la Administración, sino basta con que haya sido declarado por ella dentro de este término; lo contrario significaría limitar la competencia de la Administración para expedir el acto."

En esta oportunidad la Sala reitera la postura de que el acto administrativo por medio del cual se declara el siniestro debe ser expedido por la Administración Pública a más tardar dentro de los dos años siguientes a la fecha en la cual ésta tenga conocimiento de la ocurrencia del siniestro, hecho que necesariamente deberá acaecer durante la vigencia del seguro, aunque la declaratoria se produzca después de su vencimiento."

El Consejo de Estado ha sintetizado de esta manera las diferencias entre caducidad y prescripción de la siguiente manera, en auto de 27 de mayo de 2004. Rad. 24371, con ponencia del Doctor Alier Eduardo Hernández Enríquez.

"Sintetizando, las diferencias que separan las dos instituciones, de acuerdo con la jurisprudencia citada, son, entonces, las siguientes: La caducidad se refiere a la extinción de la acción, mientras que la prescripción a la del derecho; la primera debe ser alegada, mientras que la caducidad opera ipso iure; la prescripción es renunciable, mientras que la caducidad no lo es, en ningún caso, y mientras que los términos de prescripción pueden ser suspendidos o interrumpidos, los de caducidad no son susceptibles de suspensión, salvo expresa norma legal, como es el caso de la conciliación prejudicial establecida en la Ley 640 de 2001. Queda claro, pues, que se trata de dos figuras que regulan fenómenos diferentes y, que, en consecuencia, no es posible aplicar las normas que regulan la prescripción a la caducidad, o viceversa. Estas premisas permiten concluir que el artículo 41 de la Ley 153 de 1887 no es aplicable al presente caso, dado que dicha disposición sólo se refiere a los términos de prescripción y no a las de caducidad."

Esta sentencia resulta de gran importancia, adicionalmente para ilustrar la posición del Consejo de Estado en torno a la vigencia de las normas sobre prescripción y caducidad en el tiempo, sobre lo cual ha existido tradicionalmente una discusión en torno a si se aplican los artículos 40 y 41 de la Ley 153 de 1887 o el artículo 38 de la misma norma. En este caso se consideró que las normas que regulan la caducidad no son normas de carácter procesal sino sustancial y que por ello, respecto de ellas rigen las normas vigentes en el momento de la celebración del 
contrato (supervivencia de la ley anterior) y no se plantea la influencia de las leyes nuevas sobre la materia. En otras palabras, deben aplicarse las normas vigentes en el momento de celebración del contrato, por tratarse de temas no procesales que deben regirse por el artículo 38 de la Ley 153 de 1887 (se entienden incorporadas al contrato las leyes vigentes en el momento de su celebración) o, por tratarse de temas procesales deben aplicarse las leyes nuevas según lo dispuesto en los artículos 40 y 41 de la misma ley.

Actualmente el Consejo de Estado a este respecto ha regresado sobre la tesis de que las normas que regulan la caducidad o prescripción de las acciones no son de carácter procesal y sostiene que si lo son, pero la discusión se desplaza ahora al momento a partir del cual debe contarse el término que se encuentre vigente, ya que al respecto existen dos tesis: la sentada por la Corporación en el auto de 30 de enero de 2008, conforme a la cual para ello debe tenerse en cuenta el momento en que se configura el derecho que se pretende reclamar a través de la acción y, la sentada en la sentencia de 19 de febrero de 2009, que sostiene que debe tenerse en cuenta es el momento en que se presenta la demanda. Veamos:

Auto de 30 de enero:

"Pues bien, hecha la precisión que antecede y teniendo presente el marco que se ha expuesto acerca del carácter procesal de las normas que regulan la caducidad de las acciones y las implicaciones que de ello se derivan, hay lugar a señalar que -con excepción de los eventos en que se pretenda la nulidad del contrato, casos en los cuales el término correspondiente empezará a correr a partir de la respectiva celebración-, para la Sala el cómputo del término de caducidad de la acción, de manera general, debe iniciar a partir del momento en que i) ocurrió la terminación del correspondiente contrato, si fuere de aquellos que no requiere liquidación o ii) a partir del momento en que se efectuó su liquidación, si a ella se hubiere procedido o iii) caso de no haberse efectuado tal liquidación cuando a la misma había lugar a partir del momento en el cual debió haberse producido la correspondiente liquidación..." (subraya la Sala).

\section{La caducidad en el caso concreto}

En este orden de ideas, según tesis mayoritaria de la Sala, si la norma procesal que debe ser aplicada para efectos del ejercicio oportuno de la acción contractual es aquella vigente al momento en que se reúnan las condiciones, se configuren las circunstancias o exigencias o se hayan reunido los presupuestos requeridos en cada caso para solicitar de la jurisdicción un pronunciamiento acerca de las pretensiones correspondientes, se considera que le asiste razón al a quo cuando encontró configurada la caducidad y, en tal virtud, rechazó la demanda."

Sentencia de 19 de febrero de 2009:

“En efecto, si bien la demanda se presentó el 25 de mayo de 1999, es decir en vigencia del término de caducidad de 5 años previsto en el numeral 11 del 
artículo 44 de la Ley 46 de 1998, el cual, en principio, debía aplicarse en forma inmediata por tratarse de una disposición de carácter procesal, lo cierto que es que los términos de caducidad empezaron a correr desde el momento en el cual la obligación se hizo exigible, es decir, desde cuando se notificó la declaratoria del siniestro y se ordenó hacer efectiva la cláusula penal pecuniaria -28 agosto de 1996-, fecha para la cual se encontraba vigente el artículo 2536 del Código Civil, disposición que con anterioridad a la modificación introducida por la Ley 791 del 27 de diciembre de 2002, establecía un término de caducidad para las acciones ejecutivas de 10 años, por manera que el plazo para presentar la demanda de la referencia vencía el 28 de agosto de 2006.

En este caso, la demanda se presentó el 25 de mayo de 1999, cuando aún no habían transcurrido los 10 años de que trata el artículo 2536 del Código Civil para que operara el fenómeno de caducidad de la acción, lo cual permite concluir que carecen de fundamento los argumentos de la recurrente encaminados a sostener que cuando se notificó el segundo mandamiento de pago, esto es el 18 de marzo de 2002, había caducado la oportunidad procesal para iniciar el trámite de la acción ejecutiva. Lo anterior sin perjuicio de señalar que los actos administrativos a ejecutar podrían haber perdido fuerza ejecutoria, circunstancia que habrá de analizarse."

Las sentencias de 11 de octubre de 2006, expediente 30566, y 19 de febrero de 2009, radicación 2000-01720, ilustran con matices diferentes esta materia y lo mismo hace el salvamento de voto formulada por la Doctora Ruth Stella Correa Palacio, respecto de la última providencia mencionada.

Si las diferencias entre las dos figuras se traducen en sus consecuencias y no en su propia naturaleza, la única manera de distinguir cuando un término es de caducidad y cuando es de prescripción, vendría a reducirse al texto literal de la norma que consagre cada término: será de caducidad si la norma se refiere a ese término en particular o a la acción o recurso judicial, y será de prescripción si la norma utiliza este término o se refiere a derechos personas diferentes al derecho de acción. Pero la situación sigue siendo confusa, si se tiene en normas como la contenida en el artículo 1.081 se refieren a la prescripción de "los derechos y acciones" que surgen del contrato de seguro, y que la jurisprudencia, entre otras del Consejo de Estado, suele denominar indistintamente los términos de prescripción y caducidad, cosa que sucede precisamente cuando hace referencia a este tema referente a las acciones que nacen del seguro de cumplimiento de contratos estatales. Un ejemplo de ello se observa claramente tanto en la sentencia comentada del 19 de febrero de 2008, como en el salvamento de voto correspondiente.

Este tema, a nuestro juicio, sigue pues pendiente de una regulación expresa, o de una doctrina más consecuente con la realidad legal, que se decida de una vez a aplicar las normas generales del Código de Comercio que regulan el contrato de seguro, o las normas que regulan la caducidad de las acciones que se adelantan ante la 
Jurisdicción Contencioso Administrativa. Lo cierto es que, por el momento la situación es realmente contradictoria: si el siniestro está constituido por el acto administrativo, la prescripción no podría comenzar a contar sino desde la expedición del acto, pero en ese caso, tampoco el acto administrativo podría ser expedido por fuera de la vigencia de la póliza. Eso hace incoherente la doctrina del Consejo de Estado, en el sentido de que el acto puede producirse en cualquier tiempo, pero dentro de los dos años siguientes al incumplimiento del contratista (cuando todavía no ha ocurrido siniestro) y aún por fuera de la vigencia de la póliza, y que esos son los dos años a los que se refiere el artículo 1.081 del C. de Co. El que sería aplicable a mi juicio hoy, de no quererse aplicar el artículo 1.081 del C. de Co. es el numeral 10 del artículo 136 del C.C.A.: esto es, un término de caducidad de dos años de la acción contractual, que se cuentan a partir del momento de la ocurrencia de los motivos de hecho o de derecho que le sirven de fundamento. Esto obligaría a las entidades estatales a expedir el acto administrativo dentro del periodo de vigencia de la póliza y a contar el término de dos años a partir de allí, sin perjuicio de la posibilidad, si no quieren hacer uso de la vía ejecutiva, de acudir al juez del contrato dentro de los dos años siguientes al momento en que tengan conocimiento del incumplimiento del contratista o de cualquier otro hecho que implique la realización de los riesgos cubiertos por la póliza, por la vía ordinaria, considerándose en este caso que el siniestro, por decisión de la entidad estatal no se configurará necesariamente a través de la expedición de ningún acto administrativo sino dado el hecho del incumplimiento y con el objeto de que sea el juez del contrato el que así lo declare.

\section{CONCLUSIONES}

A manera de conclusiones, podrían deducirse las siguientes:

La nueva legislación contenida en la Ley 1150 y en su decreto reglamentario, deja todavía mucho que desear; su redacción es confusa y contradictoria y deja abiertas todavía dudas muy fundadas sobre la legalidad de las facultades que se pretenden otorgar en forma definitiva a las entidades públicas para hacer efectivas las garantías contenidas en seguros de cumplimiento; sobre los mecanismos que se han implementado para fortalecer su eficacia sobre la base de sustraer la regulación de este seguro a las reglas que rigen este negocio jurídico en el Código de Comercio. Además de ello, la ausencia de precisión sobre los temas de vía procesal (proceso ejecutivo o proceso ordinario) y de jurisdicción aplicable (coactiva, ordinaria o Contencioso Administrativa) conducen a que continúe la vacilación jurisprudencial sobre estas materias, la discusión inacabable al respecto en el seno de la Sección III del Consejo de Estado y entre las secciones del mismo organismo. Igualmente, la falta de definición sobre el tema de las normas de prescripción o caducidad que deben ser aplicados en este caso, siguen dejando en la nebulosa este tema.

Lo anterior demuestra que los remiendos que permanentemente pretenden hacerse a la legislación sobre esta materia, resultan infructuosos y, por el contrario 
mantienen los problemas tradicionales y crean nuevos problemas, algo que a nuestra manera de ver continuará mientras se trate de mantener el sistema de garantía con base en pólizas de seguro de cumplimiento, y de dar a la vez prerrogativas y facultades que desbordan los marcos tradicionales y la filosofía que inspira el estatuto de contratación administrativa, dándole a la relación entre entidades estatales aseguradas y aseguradoras un tratamiento diferente y sustancialmente más gravoso para estas últimas que el que rige para la relación entre las mismas entidades y sus contratistas. Lo anterior no solo es injustificado sino altamente inconveniente y constituye una fuente inagotable de conflictos y de desgaste consecuencial de la administración de justicia.

La insistencia en establecer un sistema que permita a las entidades conformar unilateralmente títulos ejecutivos contra las aseguradoras y utilizar consecuencialmente la vía ejecutiva para su cobro, no deja de ser un error que nace de la creencia sin fundamento de que, entre nosotros, la vía ejecutiva es más rápida y expedita que la vía ordinaria. Lo mismo ha ocurrido tradicionalmente con las disposiciones del Código de Comercio que desde hace años en Colombia han concebido, para los demás ramos de seguro, el mérito ejecutivo de la póliza dentro de ciertas circunstancias. Hacer de un contrato bilateral un título ejecutivo contra una de las partes presenta dificultades evidentes, en la medida en que un título ejecutivo es fundamentalmente un documento que proviene del deudor unilateralmente. La experiencia práctica enseña que generalmente los procesos ejecutivos que se hacen con base en pólizas de seguro demoran más tiempo y representan mayor riesgo para el demandante que generalmente se enfrenta a una discusión previa muy prolongada sobre la regularidad formal del título antes de poder entrar a discutir los aspectos de fondo de su derecho a la indemnización. La única ventaja real, y esto solo ocurre cuando se trata de otros ramos diferentes al seguro de cumplimiento de contratos estatales, es que, ante la jurisdicción civil, el proceso ejecutivo no tiene que someterse a un eventual recurso de casación; la otra gran ventaja proverbial del proceso ejecutivo, la de poder solicitar medidas preventivas contra el deudor desde el mismo momento en que se formula la demanda, no es una ventaja notable ni necesaria generalmente cuando el demandado es una compañía de seguros, cuya solvencia financiera cuenta con un sinnúmero de seguridades que derivan de la estricta vigilancia y control estatal que se ejerce sobre ellas.

Por lo mismo, no es quizás aventurado decir, que resulta por todo ello mucho más conveniente para las mismas entidades estatales, someterse a las reglas propias del contrato de seguro tal como están contenidas en el Código de Comercio, para hacer efectivos sus derechos derivados de las pólizas de seguro de cumplimiento. Sin necesidad de someterse al desgaste de todas las precauciones que deben adoptar para producir un acto administrativo, muy rápidamente a partir del momento en que tienen conocimiento de la ocurrencia del siniestro y sin perjuicio de los comportamientos que deban adoptar frente al contratista, pueden proceder a un reclamo directo ante las compañías de seguro que estarán mucho mejor dispuestas a atender ese reclamo directo que la intimación que supone la notificación de un acto administrativo con consideraciones impuestas dogmáticamente por la entidad asegurada. Ese reclamo directo, como se sabe, debe ser respondido en el término de un mes por el asegurador, 
so pena de que pueda adelantarse en su contra un proceso ejecutivo que solo tendrá como soportes la póliza y el reclamo no respondido o respondido sin fundamento o, en su lugar, si se da una objeción fundada y oportuna, pueden proceder directamente al proceso ordinario.

Para resumir, finalmente:

1. La regulación legal sobre el tema de las garantías sigue siendo muy defectuosa, aun después de la expedición de la Ley 1150 y de su decreto reglamentario.

2. No se ha resuelto aún en forma definitiva el tema de la jurisdicción aplicable para las acciones con las que cuentan las entidades estatales para hacer efectivas las pólizas de seguro de cumplimiento.

3. Debe ser expresamente aclarado que la vía ordinaria existe para hacer efectivas las pólizas.

4. No debe otorgarse a las entidades estatales la facultad de declarar el incumplimiento del contrato en cualquier tiempo.

5. Se ha menospreciado sin razón la dinámica normal de la reclamación directa que establece la regulación comercial del contrato de seguro.

6. Obligar a la vía ejecutiva es prácticamente abocar a las partes a un conflicto seguro y a proponer un debate previo de forma sobre la integridad del título ejecutivo, antes de discutir el fondo de las objeciones que eventualmente puede tener la aseguradora para el pago.

7. Lo anterior, conduce a nuestra manera de ver a explorar soluciones por las siguientes vías:

a) Eliminar el contrato de seguro de cumplimiento como forma de garantía, implementando un verdadero sistema de fianzas, a través de la creación de empresas dedicadas a ese objeto social exclusivo con vigilancia especial del Estado, como existe en otros países.

b) La misma solución, autorizando a las compañías de seguro para crear unidades administrativas separadas que operen ese ramo de negocios.

c) Mantener el sistema actual, pero eliminando el paso previo de los actos administrativos dirigidos a hacer efectivas las pólizas y estableciendo el mecanismo propio de la regulación del contrato de seguro, reclamación directa o proceso judicial. 


\section{BIBLIOGRAFÍA}

\section{Sentencias y Autos}

Sentencia de 26 de enero de 1996, expediente 0585.

Sentencia de mayo 6 de 1992, expediente 6661, ponente: Carlos Betancur Jaramillo.

Sentencia de octubre 1o de 1992, expediente 6631, ponente: Dr. Carlos Betancur Jaramillo.

Sentencia de octubre 30 de 1997, expediente 10.874 con ponencia del Dr. Daniel Suárez Hernández.

Sentencia de diciembre 10 de 1998, expediente 11446 con ponencia del Dr. Germán Rodríguez Villamizar.

Sentencia de septiembre 13 de 1991, expediente 5127. Ponente: Dr. Carlos Betancur Jaramillo. Sentencia de octubre 1o de 1992, expediente 6631. Ponente Dr. Carlos Betancur Jaramillo.

Sentencia de septiembre 18 de 1997, expediente 11524. Ponente: Dr. Jesús María Carrillo.

Sentencia de 18 de marzo de 2004, dentro del expediente 15936, publicada en Jurisprudencia y Doctrina, tomo XXXIII, No. 390, junio de 2004.

Sentencia de 13 de septiembre de 1999, expediente 10264.

Sentencia de 3 de mayo de 2001, expediente 12724.

Sentencia de 11 de diciembre de 1989. Sección III del Consejo de Estado. Consejero Ponente: Dr. Gustavo De Greiff Restrepo. Expediente 5334. Informativo jurídico de Fasecolda. No. 80.

Sentencia de agosto 20 de 1993, exp. 78.81.

Sentencia abril 13 de 2000, exp. 13342.

Sentencia julio 10 de 1997, exp. 10229.

Sentencia noviembre 13 de 2008, exp. 14584.

Corte Constitucional, sentencias T-133 de 1995; T-094 de 2000, M.P. Álvaro Tafur; T-938 de 2001, M.P. Eduardo Montealegre; T-472 de 1996; T-412 de 1992.

Sentencia de 22 de abril de 2009. Ponente: Doctora Miryam Guerrero de Escobar. Expediente 14667.

Salvamento de voto a la sentencia de 19 de febrero de 2009, expediente 24609.

Auto 1999 agosto 12, exp. 16124.

Auto 2000 agosto 03, exp. 14368.

Auto 2003 febrero 27, exp. 2349.

Auto 2003 noviembre 20, exp. 19929.

Auto de 4 de junio de 1998, exp. 13988.

\section{Libros}

Escobar Vélez, Edgar Guillermo (1999), El proceso de jurisdicción coactiva. Señal Editora. Segunda edición, Medellín.

Obando, Camilo Muñoz (1967), La fianza. Imprenta Nacional, Bogotá. 